\title{
Inherent Complexity Research on the Bullwhip Effect in Supply Chains with Two Retailers: The Impact of Three Forecasting Methods Considering Market Share
}

\author{
Junhai Ma, Binshuo Bao, and Xiaogang Ma \\ College of Management and Economics, Tianjin University, Tianjin 300072, China \\ Correspondence should be addressed to Binshuo Bao; baobinshu01024@163.com
}

Received 16 April 2014; Revised 30 June 2014; Accepted 30 June 2014; Published 4 August 2014

Academic Editor: Hamid R. Karimi

Copyright (C) 2014 Junhai Ma et al. This is an open access article distributed under the Creative Commons Attribution License, which permits unrestricted use, distribution, and reproduction in any medium, provided the original work is properly cited.

\begin{abstract}
An important phenomenon in supply chain management which is known as the bullwhip effect suggests that demand variability increases as one moves up a supply chain. This paper contrasts the bullwhip effect for a two-stage supply chain consisting of one supplier and two retailers under three forecasting methods based on the market share. We can quantify the correlation coefficient between the two retailers clearly, in consideration of market share. The two retailers both employ the order-up-to inventory policy for replenishments. The bullwhip effect is measured, respectively, under the minimum mean squared error (MMSE), moving average (MA), and exponential smoothing (ES) forecasting methods. The effect of autoregressive coefficient, lead time, and the market share on a bullwhip effect measure is investigated by using algebraic analysis and numerical simulation. And the comparison of the bullwhip effect under three forecasting methods is conducted. The conclusion suggests that different forecasting methods and various parameters lead to different bullwhip effects. Hence, the corresponding forecasting method should be chosen by the managers under different parameters in practice.
\end{abstract}

\section{Introduction}

In the research of modern logistics and supply chain management, a significant phenomenon which is called the bullwhip effect has attracted the attention of researchers and practitioners alike. As moving backward from a downstream member to an upstream member, the variance of order quantities placed by the downstream member to its immediate upstream member tends to be amplified. The first invention of the bullwhip effect could be traced back to Forrester $[1,2]$. After that, several researchers such as Blinder [3], Blanchard [4], Burbidge [5], Blinder [6] and Kahn [7], and so forth also recognized the existence of the bullwhip effect in supply chains. Sterman [8] used the Beer Game, the most popular simulation of a simple production and distribution system developed at MIT, to certificate that the bullwhip effect is an important problem. The phenomenon was firstly called the bullwhip effect by Lee et al. $[9,10]$. They indicated that the main reason for this phenomenon is demand signal processing, nonzero lead time, order batching, supply shortages, and price fluctuation.

In the five reasons mentioned above, demand signal processing is the research hotspot in this field. Metters [11] tried to identify the bullwhip effect by establishing an empirical lower bound on the profitability impact of the bullwhip effect. In his research, the impact of bullwhip effect was measured by comparing results obtained in two cases, that is, high demand variability versus low demand variability with weak seasonality. It was found that the importance of the bullwhip effect differed greatly depending on the business environment. Graves [12] quantified the bullwhip effect for the supply chain in which demand pattern follows an integrated moving average process. Chen et al. $[13,14]$ quantified the bullwhip effect for supply chains using moving average and exponential smoothing techniques for demand forecasts. In their works, it was assumed that members of the chain employ base stock policy for their inventory system. The main finding of their work was that the order variance 
would increase with the increasing number of members in the chain, lower level of information sharing, and increasing lead time. Likewise, Xu et al. [15] conducted a similar research for a demand process that was forecasted with a simple exponentially weighted moving average method. Zhang [16] also investigated the impact of different forecasting methods on the bullwhip effect for a simple inventory system with a first-order autoregressive demand process. Luong [17] measured the bullwhip effect for a simple two-stage supply chain that included only one retailer and one supplier in the environment where the retailer employed the order-upto inventory policy for their inventory and demand forecast was performed through the AR(1) model, and the effect of autoregressive coefficient and lead time on this measure was investigated. Duc et al. [18] examined the impact of a third-party warehouse on the bullwhip effect. Karimi et al. [19] considered the problem of local capacity $H_{\infty}$ control for a class of production networks of autonomous work systems with time-varying delays in the capacity changes. Nepal et al. [20] presented an analysis of the bullwhip effect and net-stock amplification in a three-echelon supply chain considering step changes in the production rates during a product's lifecycle demand. Dashkovskiy [21,22] considered local input-to-state stability of complex logistics networks. Mehrsai $[23,24]$ tried to investigate the possibility of combining this new research paradigm with existing strategies in production logistics to improve material handling and control task according to material flow criteria. Ma et al. [25] stated a comparison of bullwhip effect under various forecasting techniques in supply chains with two retailers. Shen and Jiang [26] explained the general principle of dynamic programming algorithm. Shen et al. [27] presented the dynamic programming algorithm to solve the optimal control variable trajectory under a given circle.

This paper continues to examine the differences in bullwhip effect under three forecasting methods. And this paper analyzes the impact of every parameter on the bullwhip effect. The conclusions suggest that different forecasting methods lead to bullwhip effect measures with fundamentally different properties in relation to lead time and demand autocorrelation. Therefore, the corresponding forecasting method should be selected by the managers under different parameters in practice.

The structure of this research is as follows. Section 2 depicts a new supply chain model with two retailers which both follow the AR(1) demand process and apply the orderup-to stock policy. In Section 3, the bullwhip effect measure for MMSE, MA, and ES forecasting methods is derived. In Section 4, this paper analyzes the effects of parameters on the bullwhip effect under three forecasting methods and compares the impact of three forecasting methods on the bullwhip effect. Finally, Section 5 concludes the paper with a short summary.

\section{A Supply Chain Model}

2.1. Demand Process. In this research, a two-stage supply chain with one supplier and two retailers will be considered,

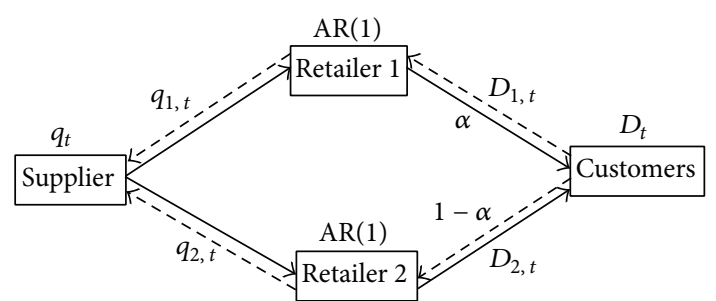

FIGURE 1: Supply chain model.

and we will quantify the bullwhip effect in the simple supply chain. The two retailers order and replenish the stock from a supplier in each period $t$. The market share of the two retailers is considered as $\alpha$ and $1-\alpha$, respectively. We assumed that the order-up-to inventory policy. Retailer 1 and retailer 2 both employ an AR(1) autoregressive model:

$$
D_{t}=\delta+\phi D_{t-1}+\varepsilon_{t} .
$$

The supply chain model shows, in Figure 1, the following:

Due to the market share of retailer 1 , we consider that retailer 1 employs an $\mathrm{AR}(1)$ model as follows:

$$
D_{1, t}=\alpha \delta_{1}+\phi_{1} D_{1, t-1}+\alpha \varepsilon_{1, t} .
$$

In (2), $D_{1, t}$ is the demand of period $t . \delta_{1}$ is the constant of the autoregressive model. $\phi_{1}$ is the first-order autocorrelation coefficient, where $-1<\phi_{1}<1 . \varepsilon_{1, t}$ is the forecast error for period $t$ and $\varepsilon_{1, t}$ is independent and identically distributed from a symmetric distribution with mean 0 and variance $\sigma_{1}^{2}$.

According to a first-order autocorrelation property of time series model, for any period $t$, we must have

$$
\begin{gathered}
E\left(D_{1, t}\right)=E\left(D_{1, t-1}\right)=\mu_{1, d}=\frac{\alpha \delta_{1}}{1-\phi_{1}}, \\
\operatorname{Var}\left(D_{1, t}\right)=\operatorname{Var}\left(D_{1, t-1}\right)=\sigma_{1, d}^{2}=\frac{\alpha^{2} \sigma_{1}^{2}}{1-\phi_{1}^{2}} .
\end{gathered}
$$

Analogously, with the market share $1-\alpha$ retailer 2 also employs an AR(1) model as follows:

$$
D_{2, t}=(1-\alpha) \delta_{2}+\phi_{2} D_{2, t-1}+(1-\alpha) \varepsilon_{2, t} .
$$

In (4), $D_{2, t}$ is the demand of period $t . \delta_{2}$ is the constant of the autoregressive model. $\phi_{2}$ is the first-order autocorrelation coefficient, where $-1<\phi_{2}<1 . \varepsilon_{2, t}$ is the forecast error for period $t$ and $\varepsilon_{2, t}$ is independent and identically distributed from a symmetric distribution with mean 0 and variance $\sigma_{2}^{2}$.

Similarly, we also have

$$
\begin{gathered}
E\left(D_{2, t}\right)=E\left(D_{2, t-1}\right)=\mu_{2, d}=\frac{(1-\alpha) \delta_{2}}{1-\phi_{2}}, \\
\operatorname{Var}\left(D_{2, t}\right)=\operatorname{Var}\left(D_{2, t-1}\right)=\sigma_{2, d}^{2}=\frac{(1-\alpha)^{2} \sigma_{2}^{2}}{1-\phi_{2}^{2}} .
\end{gathered}
$$


2.2. Inventory Policy. In order to meet the dynamic needs of the supply chain model, the supply chain model shown in Figure 1 employs the order-up-to inventory policy. We assume that the two retailers both apply a fixed order lead time for orders. The goal of the inventory policy is to maintain inventory levels at the target inventory levels $q_{t}$. At the beginning of period $t$, the order of quantity $q_{1, t}$ sent by retailer 1 can be given as follows:

$$
q_{1, t}=S_{1, t}-S_{1, t-1}+D_{1, t-1} .
$$

In (6), $S_{1, t}$ is the order-up-to level and it can be determined through lead-time demand by

$$
S_{1, t}=\widehat{D}_{1, t}^{L_{1}}+z \widehat{\sigma}_{1, t}^{L_{1}} \text {. }
$$

In (7), $\widehat{D}_{1, t}^{L_{1}}$ is the value of lead-time demand and forecast based on historical sales data. $z$ is the normal $z$-score that can be determined based on the desired service level of the inventory policy. $\widehat{\sigma}_{1, t}^{L_{1}}$ is the standard deviation of lead-time demand forecast error.

Analogously, the order of quantity sent by retailer 2 also can be given as follows:

$$
q_{2, t}=S_{2, t}-S_{2, t-1}+D_{2, t-1} .
$$

And the order-up-to level $S_{2, t}$ can be given as follows:

$$
S_{2, t}=\widehat{D}_{2, t}^{L_{2}}+z \widehat{\sigma}_{2, t}^{L_{2}}
$$

In (9), $\widehat{D}_{2, t}^{L_{2}}$ is the value of lead-time demand and forecast based on historical sales data. $z$ is the normal $z$-score that can be determined based on the desired service level of the inventory policy. $\widehat{\sigma}_{2, t}^{L_{2}}$ is the standard deviation of lead-time demand forecast error.

2.3. Forecasting Method. Seen from the inventory policy equation, the accuracy of the demand and forecasting of the future lead-time $L$ period is the most important factor that affects the inventory level of the retailers in supply chain model. While each forecasting error is present, the impacts of different forecasting methods on the bullwhip effect are not the same. Then we will introduce three different forecasting methods: MMES, MA, and ES forecasting methods.

2.3.1. The MMSE Forecasting Method. The MMSE forecasting method is short for minimizing the mean square error. Under the MMSE forecasting method, the lead-time demand can be shown as follows:

$$
D_{t}^{L}=D_{t}+D_{t+1}+\cdots+D_{t+L-1}=\sum_{i=0}^{L-1} D_{t+i} .
$$

When using the MMSE method to predict the future leadtime demand, the total demand expectations within the leadtime $L$ are

$$
\widehat{D}_{t}^{L}=\widehat{D}_{t}+\widehat{D}_{t+1}+\cdots+\widehat{D}_{t+L-1}=\sum_{i=0}^{L-1} \widehat{D}_{t+i},
$$

where $\widehat{D}_{t+i}$ can be characterized as

$$
\widehat{D}_{t+i}=E\left[D_{t+i} \mid D_{t-1}, D_{t-2}, \ldots\right] \text {. }
$$

2.3.2. The MA Forecasting Method. The MA forecasting method is short for moving average. In the MA forecasting method, the lead-time demand can be determined as follows:

$$
\widehat{D}_{t}^{L}=\frac{L}{k} \sum_{i=1}^{k} D_{t-i}
$$

In (13), $K$ is the span (number of date points) for the MA forecasting method. $D_{t-i}$ is the actual demand in period $t-i$.

2.3.3. The ES Forecasting Method. The ES forecasting method is short for exponential smoothing. Using the ES forecasting method, the lead-time demand can be considered as follows:

$$
\widehat{D}_{t}^{L}=\beta D_{t-1}+(1-\beta) \widehat{D}_{t-1}^{L}
$$

In (14), $\beta$ is the smoothing exponent.

\section{The Measure of the Bullwhip Effect}

In this section, we will talk about the measure of the bullwhip effect under the MMSE, MA, and ES forecasting methods. The total demand of the two retailers is given as

$$
D_{t}=D_{1, t}+D_{2, t}
$$

3.1. The Measure of the Bullwhip Effect under the MMSE Forecasting Method. Under the MMSE forecasting method, the total demand expectations within the lead-time $L$ of retailer 1 can be determined as

$$
\begin{aligned}
\widehat{D}_{1, t}^{L_{1}}= & \frac{L_{1}}{1-\phi_{1}} \alpha \delta_{1}-\frac{\phi_{1}\left(1-\phi_{1}{ }^{L_{1}}\right)}{\left(1-\phi_{1}\right)^{2}} \alpha \delta_{1} \\
& +\frac{\phi_{1}\left(1-\phi_{1}{ }^{L_{1}}\right)}{1-\phi_{1}} D_{1, t-1} .
\end{aligned}
$$

We know that $\widehat{\sigma}_{1, t}^{L_{1}}$ does not depend on $t$, so the order quantity of retailer 1 can be described as follows:

$$
\begin{aligned}
q_{1, t} & =\left(1+\frac{\phi_{1}\left(1-\phi_{1}{ }^{L_{1}}\right)}{1-\phi_{1}}\right) D_{1, t-1}-\frac{\phi_{1}\left(1-\phi_{1}{ }^{L_{1}}\right)}{1-\phi_{1}} D_{1, t-2} \\
& =\left(1+A_{1}\right) D_{1, t-1}-A_{1} D_{1, t-2},
\end{aligned}
$$

where $A_{1}=\phi_{1}\left(1-\phi_{1}{ }^{L_{1}}\right) /\left(1-\phi_{1}\right)$.

Similarly, we can get the order quantity of retailer 2 :

$$
\begin{aligned}
q_{2, t} & =\left(1+\frac{\phi_{2}\left(1-\phi_{2}{ }^{L_{2}}\right)}{1-\phi_{2}}\right) D_{2, t-1}-\frac{\phi_{2}\left(1-\phi_{2}{ }^{L_{2}}\right)}{1-\phi_{2}} D_{2, t-2} \\
& =\left(1+A_{2}\right) D_{2, t-1}-A_{2} D_{2, t-2},
\end{aligned}
$$

where $A_{2}=\phi_{2}\left(1-\phi_{2}{ }^{L_{2}}\right) /\left(1-\phi_{2}\right)$.

Total demand that two retailers face is

$$
D_{t}=D_{1, t}+D_{2, t} .
$$


Taking the variance of the total demand, we have

$$
\begin{aligned}
\operatorname{Var}\left(D_{t}\right) & =\operatorname{Var}\left(D_{1, t}+D_{2, t}\right) \\
& =\operatorname{Var}\left(D_{1, t}\right)+\operatorname{Var}\left(D_{2, t}\right)+2 \operatorname{Cov}\left(D_{1, t}, D_{2, t}\right) .
\end{aligned}
$$

The covariance between $D_{1, t}$ and $D_{2, t}$ can be described as

$$
\operatorname{Cov}\left(D_{1, t}, D_{2, t}\right)=\frac{\alpha}{1-\alpha} \operatorname{Var}\left(D_{2, t}\right)
$$

Total order quantity which two retailers face is $q_{t}=\left(1+A_{1}\right) D_{1, t-1}-A_{1} D_{1, t-2}+\left(1+A_{2}\right) D_{2, t-1}-A_{2} D_{2, t-2}$.

Taking the variance of the total order quantity, we have

$$
\begin{aligned}
\operatorname{Var}\left(q_{t}\right)= & \left(1+2 A_{1}+2 A_{1}^{2}\right) \operatorname{Var}\left(D_{1, t-1}\right)+\left(1+2 A_{2}+2 A_{2}^{2}\right) \\
& \times \operatorname{Var}\left(D_{2, t-1}\right)-2 A_{1}\left(1+A_{1}\right) \operatorname{Cov}\left(D_{1, t-1}, D_{1, t-2}\right) \\
& +2\left(1+A_{1}\right)\left(1+A_{2}\right) \operatorname{Cov}\left(D_{1, t-1}, D_{2, t-1}\right)-2 A_{2} \\
& \times\left(1+A_{1}\right) \operatorname{Cov}\left(D_{1, t-1}, D_{2, t-2}\right)-2 A_{1}\left(1+A_{2}\right) \\
& \times \operatorname{Cov}\left(D_{1, t-2}, D_{2, t-1}\right)+2 A_{1} A_{2} \operatorname{Cov}\left(D_{1, t-2}, D_{2, t-2}\right) \\
& -2 A_{2}\left(1+A_{2}\right) \operatorname{Cov}\left(D_{2, t-1}, D_{2, t-2}\right) .
\end{aligned}
$$

We can prove that

$$
\begin{aligned}
& \operatorname{Cov}\left(D_{1, t-1}, D_{1, t-2}\right)=\phi_{1} \operatorname{Var}\left(D_{1, t}\right), \\
& \operatorname{Cov}\left(D_{1, t-1}, D_{2, t-1}\right)=\frac{\alpha}{1-\alpha} \operatorname{Var}\left(D_{2, t}\right), \\
& \operatorname{Cov}\left(D_{1, t-1}, D_{2, t-2}\right)=\phi_{1} \frac{\alpha}{1-\alpha} \operatorname{Var}\left(D_{2, t}\right), \\
& \operatorname{Cov}\left(D_{1, t-2}, D_{2, t-1}\right)=\phi_{2} \frac{\alpha}{1-\alpha} \operatorname{Var}\left(D_{2, t}\right), \\
& \operatorname{Cov}\left(D_{1, t-2}, D_{2, t-2}\right)=\frac{\alpha}{1-\alpha} \operatorname{Var}\left(D_{2, t}\right), \\
& \operatorname{Cov}\left(D_{2, t-1}, D_{2, t-2}\right)=\phi_{2} \operatorname{Var}\left(D_{2, t}\right) .
\end{aligned}
$$

Therefore, (23) can be described as

$$
\begin{aligned}
\operatorname{Var}\left(q_{t}\right)= & \left(1+2 A_{1}+2 A_{1}^{2}-2 A_{1}\left(1+A_{1}\right) \phi_{1}\right) \operatorname{Var}\left(D_{1, t}\right) \\
+ & \left(1+2 A_{2}+2 A_{2}^{2}-2 A_{2}\left(1+A_{2}\right) \phi_{2}\right) \operatorname{Var}\left(D_{2, t}\right) \\
+ & \left(2+2\left(A_{1}+A_{2}\right)+3 A_{1} A_{2}-2 \phi_{1} A_{2}\left(1+A_{1}\right)\right. \\
& \left.-2 \phi_{2} A_{1}\left(1+A_{2}\right)\right) \frac{\alpha}{1-\alpha} \operatorname{Var}\left(D_{2, t}\right)
\end{aligned}
$$

For simplicity, (25) can be written as

$$
\begin{aligned}
\operatorname{Var}\left(q_{t}\right)= & G_{1} \operatorname{Var}\left(D_{1, t}\right)+G_{2} \operatorname{Var}\left(D_{2, t}\right) \\
& +G_{3} \frac{\alpha}{1-\alpha} \operatorname{Var}\left(D_{2, t}\right) .
\end{aligned}
$$

In (26) $G_{1}$ is the coefficient of $\operatorname{Var}\left(D_{1, t}\right), G_{2}$ is the coefficient of $\operatorname{Var}\left(D_{2, t}\right)$, and $G_{3}$ is the coefficient of $\alpha /(1-$ a) $\operatorname{Var}\left(D_{2, t}\right)$.

Then, the BWE in MMSE forecasting method is

$$
\operatorname{BWE}_{\mathrm{MMSE}}=\frac{\operatorname{Var}\left(q_{t}\right)}{\operatorname{Var}\left(D_{t}\right)}=\frac{\alpha^{2} G_{1}+(1-\alpha)^{2} G_{2}+\alpha(1-\alpha) G_{3}}{\alpha^{2}+(1-\alpha)^{2}+2 \alpha(1-\alpha)} .
$$

3.2. The Measure of the Bullwhip Effect under the MA Forecasting Method. In the MA forecasting method, the lead-time demand of retailer 1 can be determined as follows:

$$
\widehat{D}_{1, t}^{L_{1}}=\frac{L_{1}}{k} \sum_{i=1}^{k} D_{1, t-i}
$$

Therefore, the total order quantity of the two retailers is

$$
\begin{aligned}
q_{t}= & \left(1+\frac{L_{1}}{k}\right) D_{1, t-1}-\frac{L_{1}}{k} D_{1, t-k-1}+\left(1+\frac{L_{2}}{k}\right) D_{2, t-1} \\
& -\frac{L_{2}}{k} D_{2, t-k-1} .
\end{aligned}
$$

Taking the variance of the total order quantity, we have

$$
\begin{aligned}
\operatorname{Var}\left(q_{t}\right)= & \left(1+\frac{L_{1}}{k}\right)^{2} \operatorname{Var}\left(D_{1, t-1}\right)+\left(\frac{L_{1}}{k}\right)^{2} \operatorname{Var}\left(D_{1, t-k-1}\right) \\
& +\left(1+\frac{L_{2}}{k}\right)^{2} \operatorname{Var}\left(D_{2, t-1}\right)+\left(\frac{L_{2}}{k}\right)^{2} \operatorname{Var}\left(D_{2, t-k-1}\right) \\
& -2\left(1+\frac{L_{1}}{k}\right) \frac{L_{1}}{k} \operatorname{Cov}\left(D_{1, t-1}, D_{1, t-k-1}\right) \\
& +2\left(1+\frac{L_{1}}{k}\right)\left(1+\frac{L_{2}}{k}\right) \operatorname{Cov}\left(D_{1, t-1}, D_{2, t-1}\right) \\
& -2\left(1+\frac{L_{1}}{k}\right) \frac{L_{2}}{k} \operatorname{Cov}\left(D_{1, t-1}, D_{2, t-k-1}\right) \\
& -2 \frac{L_{1}}{k}\left(1+\frac{L_{2}}{k}\right) \operatorname{Cov}\left(D_{1, t-k-1}, D_{2, t-1}\right) \\
& +2 \frac{L_{1}}{k} \frac{L_{2}}{k} \operatorname{Cov}\left(D_{1, t-k-1}, D_{2, t-k-1}\right) \\
& -2\left(1+\frac{L_{2}}{k}\right) \frac{L_{2}}{k} \operatorname{Cov}\left(D_{2, t-1}, D_{2, t-k-1}\right)
\end{aligned}
$$


We can prove that

$$
\begin{aligned}
\operatorname{Cov}\left(D_{1, t-1}, D_{1, t-k-1}\right) & =\phi_{1}{ }^{k} \operatorname{Var}\left(D_{1, t}\right), \\
\operatorname{Cov}\left(D_{1, t-1}, D_{2, t-1}\right) & =\frac{\alpha}{1-\alpha} \operatorname{Var}\left(D_{2, t}\right), \\
\operatorname{Cov}\left(D_{1, t-1}, D_{2, t-k-1}\right) & =\phi_{1}{ }^{k} \frac{\alpha}{1-\alpha} \operatorname{Var}\left(D_{2, t}\right), \\
\operatorname{Cov}\left(D_{1, t-k-1}, D_{2, t-1}\right) & =\phi_{2}{ }^{k} \frac{\alpha}{1-\alpha} \operatorname{Var}\left(D_{2, t}\right), \\
\operatorname{Cov}\left(D_{1, t-k-1}, D_{2, t-k-1}\right) & =\frac{\alpha}{1-\alpha} \operatorname{Var}\left(D_{2, t}\right), \\
\operatorname{Cov}\left(D_{2, t-1}, D_{2, t-k-1}\right) & =\phi_{2}{ }^{k} \operatorname{Var}\left(D_{2, t}\right) .
\end{aligned}
$$

The proof of (31) can be seen in the Appendix.

Then, taking (31) into (30), we have

$\operatorname{Var}\left(q_{t}\right)$

$$
\begin{gathered}
=\left(1+2 \frac{L_{1}}{k}+2\left(\frac{L_{1}}{k}\right)^{2}-2 \phi_{1}^{k}\left(1+\frac{L_{1}}{k}\right) \frac{L_{1}}{k}\right) \operatorname{Var}\left(D_{1, t}\right) \\
+\left(1+2 \frac{L_{2}}{k}+2\left(\frac{L_{2}}{k}\right)^{2}-2 \phi_{2}{ }^{k}\left(1+\frac{L_{2}}{k}\right) \frac{L_{2}}{k}\right) \operatorname{Var}\left(D_{2, t}\right) \\
+2\left(\left(1+\frac{L_{1}}{k}\right)\left(1+\frac{L_{2}}{k}\right)-\left(1+\frac{L_{1}}{k}\right) \frac{L_{2}}{k} \phi_{1}^{k}\right. \\
\left.-\frac{L_{1}}{k}\left(1+\frac{L_{2}}{k}\right) \phi_{2}{ }^{k}+\frac{L_{1} L_{2}}{k}\right) \frac{\alpha}{1-\alpha} \operatorname{Var}\left(D_{2, t}\right) .
\end{gathered}
$$

For simplicity, (32) can be written as

$$
\begin{aligned}
\operatorname{Var}\left(q_{t}\right)= & H_{1} \operatorname{Var}\left(D_{1, t}\right)+H_{2} \operatorname{Var}\left(D_{2, t}\right) \\
& +H_{3} \frac{\alpha}{1-\alpha} \operatorname{Var}\left(D_{2, t}\right) .
\end{aligned}
$$

In (33) $H_{1}$ is the coefficient of $\operatorname{Var}\left(D_{1, t}\right), H_{2}$ is the coefficient of $\operatorname{Var}\left(D_{2, t}\right)$, and $H_{3}$ is the coefficient of $\alpha /(1-$ a) $\operatorname{Var}\left(D_{2, t}\right)$.

Then, the BWE in MMSE forecasting method is

$$
\mathrm{BWE}_{\mathrm{MA}}=\frac{\operatorname{Var}\left(q_{t}\right)}{\operatorname{Var}\left(D_{t}\right)}=\frac{\alpha^{2} H_{1}+(1-\alpha)^{2} H_{2}+\alpha(1-\alpha) H_{3}}{\alpha^{2}+(1-\alpha)^{2}+2 \alpha(1-\alpha)} .
$$

3.3. The Measure of the Bullwhip Effect under the ES Forecasting Method. Using the ES forecasting method, the lead-time demand of retailer 1 can be determined as follows:

$$
\widehat{D}_{1, t}^{L_{1}}=\beta D_{1, t-1}+(1-\beta) \widehat{D}_{1, t-1}^{L_{1}} .
$$

According to Zhang [16], $\widehat{D}_{t+i}=\widehat{D}_{t+1}, i \geq 2$, the total order quantity of two retailers at period $t$ is

$$
q_{t}=\left(1+\beta_{1} L_{1}\right) D_{1, t}-\beta_{1} L_{1} \widehat{D}_{1, t}+\left(1+\beta_{2} L_{2}\right) D_{2, t}-\beta_{2} L_{2} \widehat{D}_{2, t} .
$$

Taking the variance of the total order quantity, we have

$$
\begin{aligned}
\operatorname{Var}\left(q_{t}\right)= & \left(1+\beta_{1} L_{1}\right)^{2} \operatorname{Var}\left(D_{1, t}\right)+\left(\beta_{1} L_{1}\right)^{2} \operatorname{Var}\left(\widehat{D}_{1, t}\right) \\
& +\left(1+\beta_{2} L_{2}\right)^{2} \operatorname{Var}\left(D_{2, t}\right)+\left(\beta_{2} L_{2}\right)^{2} \operatorname{Var}\left(\widehat{D}_{2, t}\right) \\
& -2 \beta_{1} L_{1}\left(1+\beta_{1} L_{1}\right) \operatorname{Cov}\left(D_{1, t}, \widehat{D}_{1, t}\right) \\
& +2\left(1+\beta_{1} L_{1}\right)\left(1+\beta_{2} L_{2}\right) \operatorname{Cov}\left(D_{1, t}, D_{2, t}\right) \\
& -2 \beta_{2} L_{2}\left(1+\beta_{1} L_{1}\right) \operatorname{Cov}\left(D_{1, t}, \widehat{D}_{2, t}\right) \\
& -2 \beta_{1} L_{1}\left(1+\beta_{2} L_{2}\right) \operatorname{Cov}\left(\widehat{D}_{1, t}, D_{2, t}\right) \\
& +2 \beta_{1} L_{1} \beta_{2} L_{2} \operatorname{Cov}\left(\widehat{D}_{1, t}, \widehat{D}_{2, t}\right) \\
& -2 \beta_{2} L_{2}\left(1+\beta_{2} L_{2}\right) \operatorname{Cov}\left(D_{2, t}, \widehat{D}_{2, t}\right) .
\end{aligned}
$$

According to Zhang [16], we know that

$\operatorname{Var}\left(\widehat{D}_{1, t}\right)=\frac{1+\left(1-\beta_{1}\right) \phi_{1}}{\beta_{1}\left(2-\beta_{1}\right)\left(1-\left(1-\beta_{1}\right) \phi_{1}\right)} \operatorname{Var}\left(D_{1, t}\right)$,

$\operatorname{Var}\left(\widehat{D}_{2, t}\right)=\frac{1+\left(1-\beta_{2}\right) \phi_{2}}{\beta_{2}\left(2-\beta_{2}\right)\left(1-\left(1-\beta_{2}\right) \phi_{2}\right)} \operatorname{Var}\left(D_{2, t}\right)$.

We can prove that

$$
\begin{gathered}
\operatorname{Cov}\left(D_{1, t}, \widehat{D}_{1, t}\right)=\frac{\beta_{1} \phi_{1}}{1-\left(1-\beta_{1}\right) \phi_{1}} \operatorname{Var}\left(D_{1, t}\right), \\
\operatorname{Cov}\left(D_{1, t}, D_{2, t}\right)=\frac{\alpha}{1-\alpha} \operatorname{Var}\left(D_{2, t}\right),
\end{gathered}
$$

$\operatorname{Cov}\left(D_{1, t}, \widehat{D}_{2, t}\right)=\frac{\beta_{2} \phi_{1}}{1-\left(1-\beta_{2}\right) \phi_{1}} \frac{\alpha}{1-\alpha} \operatorname{Var}\left(D_{2, t}\right)$,

$\operatorname{Cov}\left(\widehat{D}_{1, t}, D_{2, t}\right)=\frac{\beta_{1} \phi_{2}}{1-\left(1-\beta_{1}\right) \phi_{2}} \frac{\alpha}{1-\alpha} \operatorname{Var}\left(D_{2, t}\right)$,

$$
\begin{aligned}
& \operatorname{Cov}\left(\widehat{D}_{1, t}, \widehat{D}_{2, t}\right) \\
&=\left(\beta_{1} \beta_{2}\left(1-\phi_{1} \phi_{2}\left(1-\beta_{1}\right)\left(1-\beta_{2}\right)\right)\right) \\
& \quad\left(\left(1-\left(1-\beta_{1}\right)\left(1-\beta_{2}\right)\right)\left(1-\left(1-\beta_{1}\right) \phi_{2}\right)\right. \\
&\left.\times\left(1-\left(1-\beta_{2}\right) \phi_{1}\right)\right)^{-1} \frac{\alpha}{1-\alpha} \operatorname{Var}\left(D_{2, t}\right), \\
& \operatorname{Cov}\left(D_{2, t}, \widehat{D}_{2, t}\right)=\frac{\beta_{2} \phi_{2}}{1-\left(1-\beta_{2}\right) \phi_{2}} \operatorname{Var}\left(D_{2, t}\right) .
\end{aligned}
$$

The proof of (39) can be seen in the Appendix. 
Then, taking (39) into (37), we can get

$$
\begin{aligned}
& \operatorname{Var}\left(q_{t}\right) \\
& =\left(1+\frac{1-\phi_{1}}{1-\left(1-\beta_{1}\right) \phi_{1}}\left(2 \beta_{1} L_{1}+\frac{2 \beta_{1}{ }^{2} L_{1}{ }^{2}}{2-\beta_{1}}\right)\right) \operatorname{Var}\left(D_{1, t}\right) \\
& +\left(1+\frac{1-\phi_{2}}{1-\left(1-\beta_{2}\right) \phi_{2}}\left(2 \beta_{2} L_{2}+\frac{2 \beta_{2}{ }^{2} L_{2}^{2}}{2-\beta_{2}}\right)\right) \operatorname{Var}\left(D_{2, t}\right) \\
& +\left(2\left(1+\beta_{1} L_{1}\right)\left(1+\beta_{2} L_{2}\right)-\frac{2 \beta_{2}{ }^{2} \phi_{1} L_{2}\left(1+\beta_{1} L_{1}\right)}{1-\left(1-\beta_{2}\right) \phi_{1}}\right. \\
& \quad-\frac{2 \beta_{1}{ }^{2} \phi_{2} L_{2}\left(1+\beta_{2} L_{2}\right)}{1-\left(1-\beta_{1}\right) \phi_{2}} \\
& \left.+\frac{2 \beta_{1}^{2} \beta_{2}{ }^{2}\left(1-\phi_{1} \phi_{2}\left(1-\beta_{1}\right)\left(1-\beta_{2}\right)\right)}{2 \beta_{1}{ }^{2} \beta_{2}{ }^{2}\left(1-\phi_{1} \phi_{2}\left(1-\beta_{1}\right)\left(1-\beta_{2}\right)\right)\left(1-\left(1-\beta_{2}\right) \phi_{1}\right)}\right) \\
& \times \frac{\alpha}{1-\alpha} \operatorname{Var}^{2}\left(D_{2, t}\right) .
\end{aligned}
$$

For simplicity, (40) can be written as

$$
\begin{aligned}
\operatorname{Var}\left(q_{t}\right)= & M_{1} \operatorname{Var}\left(D_{1, t}\right)+M_{2} \operatorname{Var}\left(D_{2, t}\right) \\
& +M_{3} \frac{\alpha}{1-\alpha} \operatorname{Var}\left(D_{2, t}\right) .
\end{aligned}
$$

In (41) $M_{1}$ is the coefficient of $\operatorname{Var}\left(D_{1, t}\right), M_{2}$ is the coefficient of $\operatorname{Var}\left(D_{2, t}\right)$, and $M_{3}$ is the coefficient of $\alpha /(1-$ a) $\operatorname{Var}\left(D_{2, t}\right)$.

Then, the BWE in ES forecasting method is

$$
\begin{aligned}
\mathrm{BWE}_{\mathrm{ES}} & =\frac{\operatorname{Var}\left(q_{t}\right)}{\operatorname{Var}\left(D_{t}\right)} \\
& =\frac{M_{1} \operatorname{Var}\left(D_{1, t}\right)+M_{2}+M_{3}(\alpha /(1-\alpha)) \operatorname{Var}\left(D_{2, t}\right)}{\operatorname{Var}\left(D_{1, t}\right)+\operatorname{Var}\left(D_{2, t}\right)+2(\alpha /(1-\alpha)) \operatorname{Var}\left(D_{2, t}\right)} \\
& =\frac{M_{1}\left(\operatorname{Var}\left(D_{1, t}\right) / \operatorname{Var}\left(D_{2, t}\right)\right)+M_{2}+m_{3}(\alpha /(1-\alpha))}{\left(\operatorname{Var}\left(D_{1, t}\right) / \operatorname{Var}\left(D_{2, t}\right)\right)+1+2(\alpha /(1-\alpha))} \\
& =\frac{M_{1}(\alpha /(1-\alpha))^{2}+M_{2}+M_{3}(\alpha /(1-\alpha))}{(\alpha /(1-\alpha))^{2}+1+2(\alpha /(1-\alpha))} \\
& =\frac{\alpha^{2} M_{1}+(1-\alpha)^{2} M_{2}+\alpha(1-\alpha) M_{3}}{\alpha^{2}+(1-\alpha)^{2}+2 \alpha(1-\alpha)} .
\end{aligned}
$$

\section{Behavior of the Bullwhip Effect Measure and Numerical Simulation}

With the expression of the bullwhip effect under three forecasting methods, we can discuss the bullwhip effect by algebraic analysis and numerical simulation.

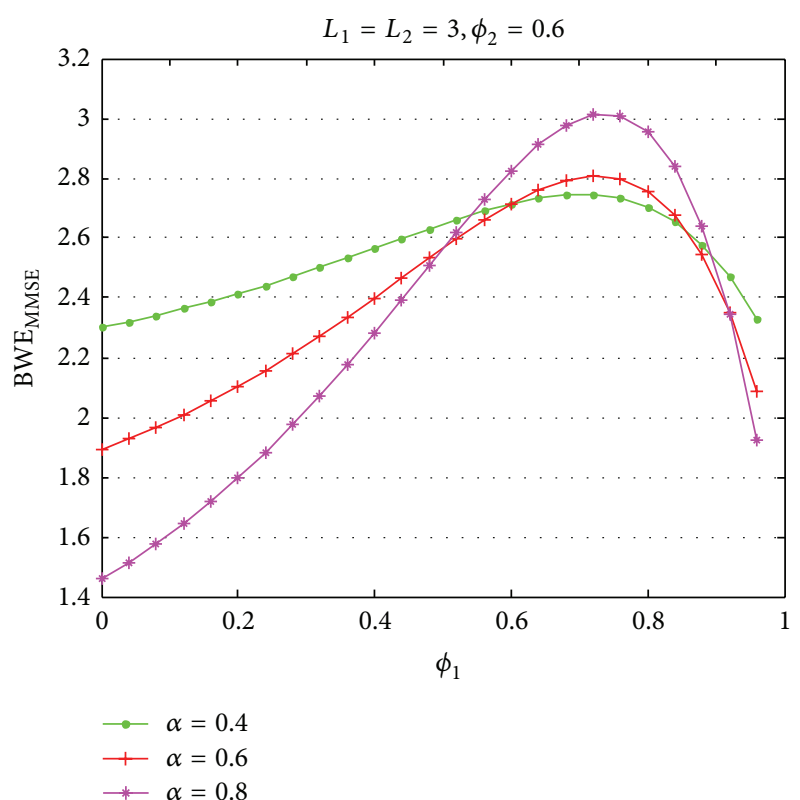

FIGURE 2: Impact of $\phi_{1}$ on bullwhip effect for different $\alpha$ under the MMSE.

4.1. The Analysis of Parameters under the MMSE Forecasting Method. Figures 2-4 simulate the expression of the bullwhip effect under the MMSE forecasting method to illustrate the impact of parameters on the bullwhip effect. Duc et al. [28] indicated that the bullwhip effect occurs only when a positive autoregressive relationship exists in the demand process under MMSE forecasting method. So, we just consider the circumstance that $\phi_{1}$ varies from 0 to 1 . Figure 2 indicates that the bullwhip effect increases slowly with the increase of $\phi_{1}$, and the bullwhip effect begins to decrease rapidly when it reaches the maximum value. The bullwhip effect does not occur only when $\phi_{1}$ increases to a certain value, and the values are different with different $\alpha$. For $\alpha$, when $\phi_{1}$ is smaller than a certain value, the bullwhip effect becomes smaller with $\alpha$ becoming larger, when $\phi_{1}$ is larger than that certain value and smaller than another certain value, the bullwhip effect becomes larger with $\alpha$ becoming larger, when $\phi_{1}$ is larger than another certain value, the bullwhip effect becomes smaller with $\alpha$ becoming larger.

Figure 3 reveals that the bullwhip effect decreases gradually to the minimum value and then it begins to increase with the increase of $\alpha$. For the different $L_{1}$, the larger it is, the larger the bullwhip effect is. The result suggests when retailer 1 occupies half of the market share and they set the short lead time, the bullwhip effect value will be the lowest.

Figure 4 depicts the impact of $\phi_{1}$ on the bullwhip effect. We observe that the bullwhip effect increases gradually to the maximum value with the increase of $\phi_{1}$, and the bullwhip effect begins to decrease rapidly when it reaches the maximum value. The bullwhip effect does not occur only when $\phi_{1}$ increases to a certain value, and those values are different for different $L_{1}$. For different $L_{1}$, the larger it is, the larger the bullwhip effect is. 


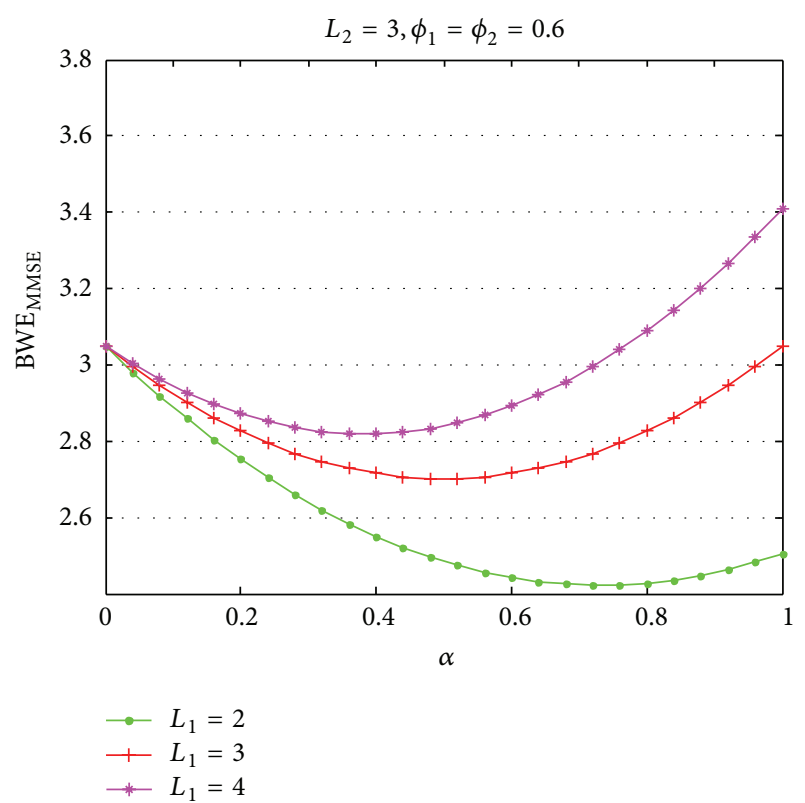

Figure 3: Impact of $\alpha$ on bullwhip effect for different $L_{1}$ under the MMSE.

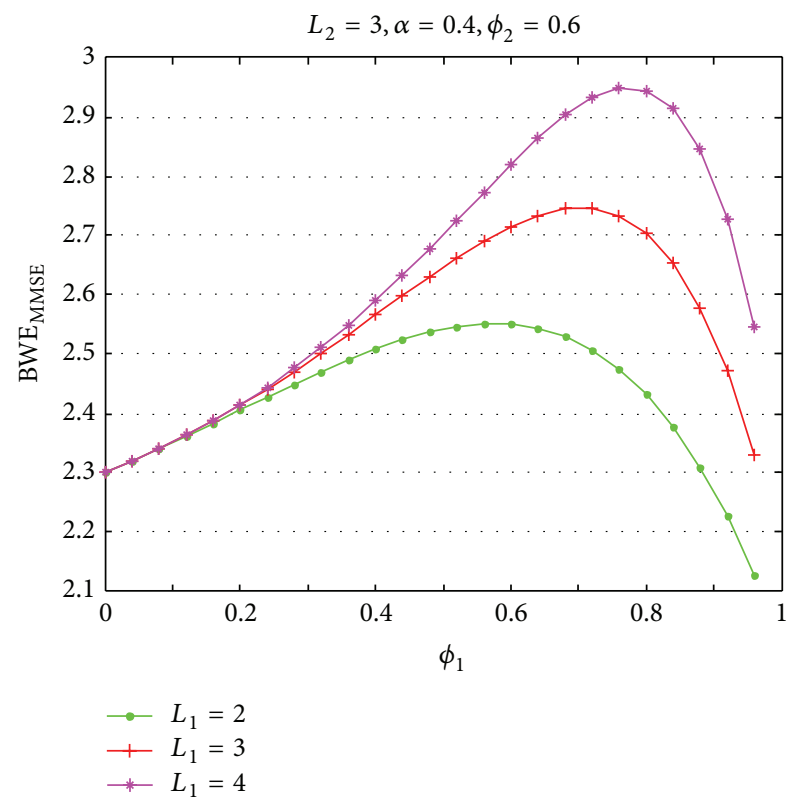

FIGURE 4: Impact of $\phi_{1}$ on bullwhip effect for different $L_{1}$ under the MMSE.

4.2. The Analysis of Parameters under the MA Forecasting Method. Figures 5-9 simulate the expression of the bullwhip effect under the MA forecasting method to illustrate the impact of parameters on the bullwhip effect.

Figure 5 shows that the bullwhip effect decreases with the increase of $\phi_{1}$. With different $\alpha$ the bullwhip effect changes only a little. So $\alpha$ hardly affects the bullwhip effect in the circumstance of different $\phi_{1}$.

Figure 6 indicates that the bullwhip effect decreases slowly all the time with the increase of $\phi_{1}$. And, in this

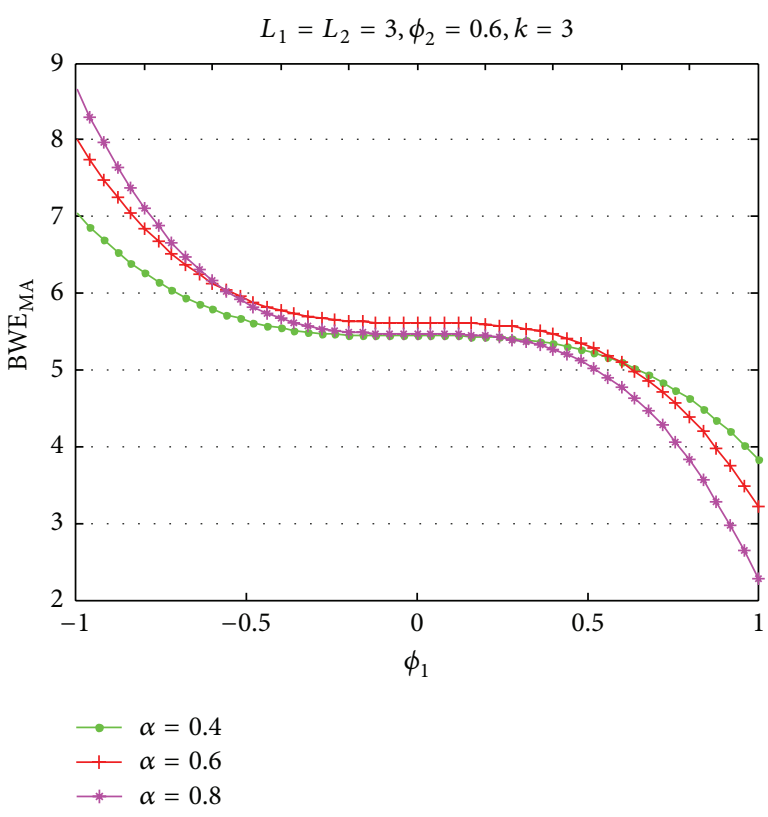

FIgURE 5: Impact of $\phi_{1}$ on bullwhip effect for different $\alpha$ under the MA.

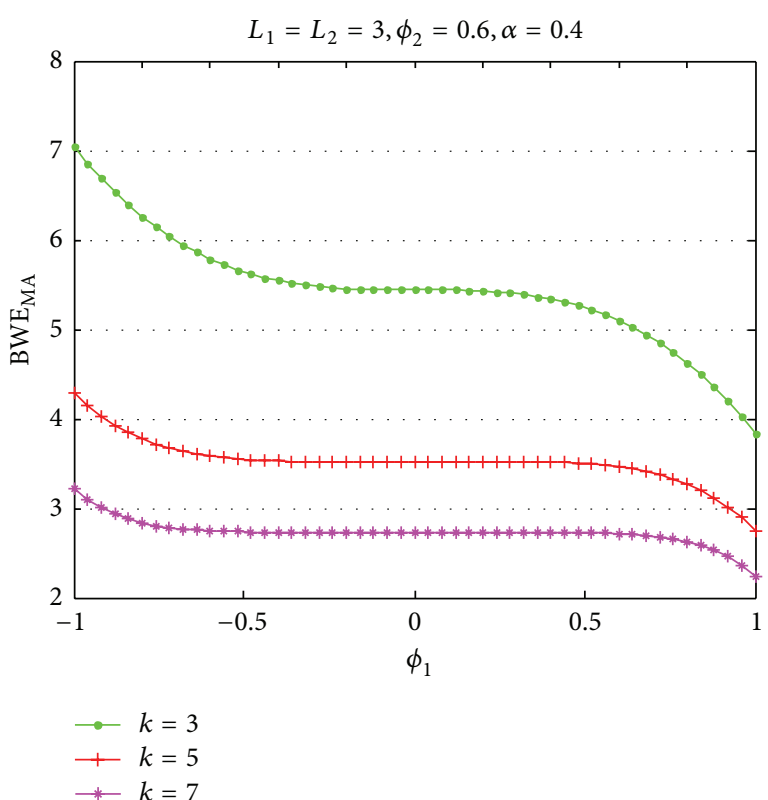

FIGURE 6: Impact of $\phi_{1}$ on bullwhip effect for different $k$ under the MA.

situation, we shift the span (number of date points) $k$ of retailer 1 , and we can find that the bullwhip effect becomes smaller with the increase of $k$. We can come to the conclusion that $k$ is a key factor to affect the bullwhip effect.

By observing Figure 7, we know when $\alpha$ takes the value of zero, the bullwhip effect value is fixed no matter what value $L_{1}$ is. Then the bullwhip effect value increases to the maximum value firstly, and after that it begins to decrease with the increase of $\alpha$. In this situation, $L_{1}$ influences the BWE obviously, the smaller the $L_{1}$ is, the smaller the BWE is. 


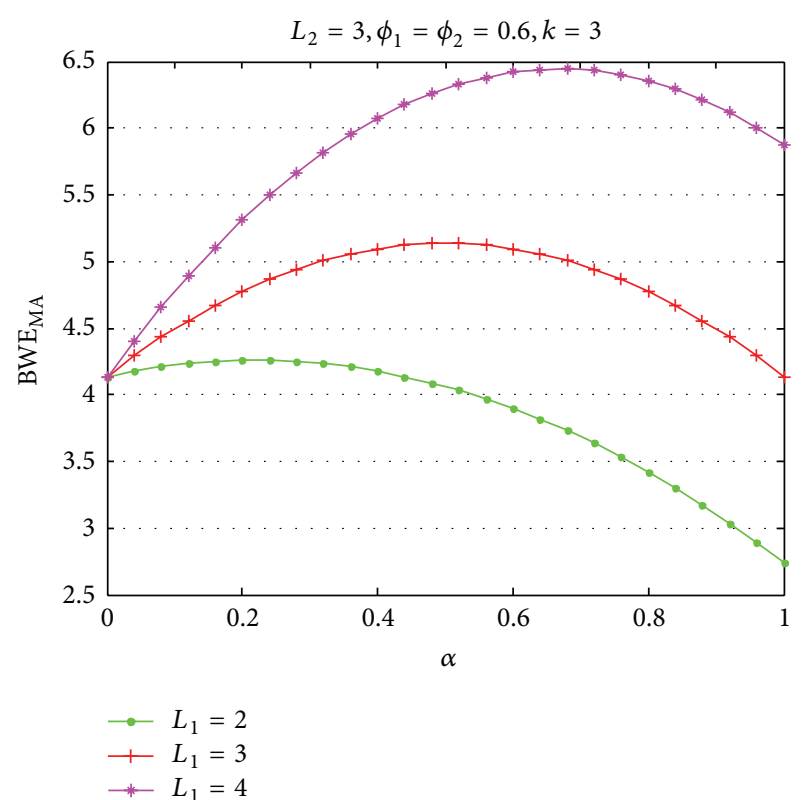

Figure 7: Impact of $\alpha$ on bullwhip effect for different $L_{1}$ under the MA.

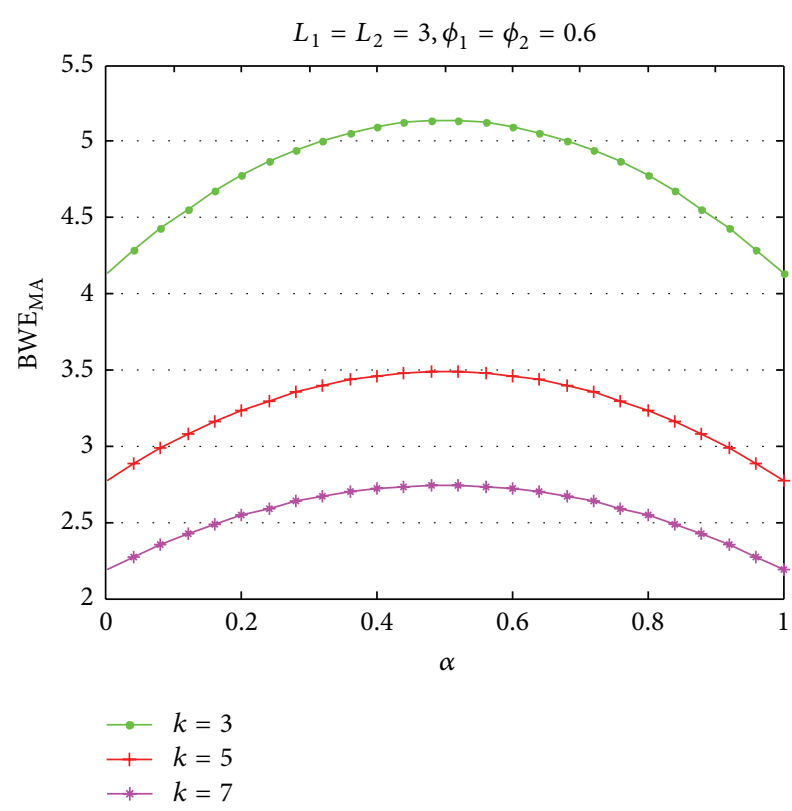

FigURE 8: Impact of $\alpha$ on bullwhip effect for different $k$ under the MA.

Figure 8 shows that the trend of the bullwhip effect is increased first to the maximum and declined gradually with the increase of $\alpha$. The larger the $k$ is, the smaller the BWE is.

Figure 9 which is similar to Figure 6 simulates the impact of $\phi_{1}$ on the bullwhip effect based on different $L_{1}$. The bullwhip effect decreases slowly all the time with the increase of $\phi_{1}$. And we may find that the $L_{1}$ influences the BWE obviously; the bullwhip effect becomes smaller with the decrease of $L_{1}$.

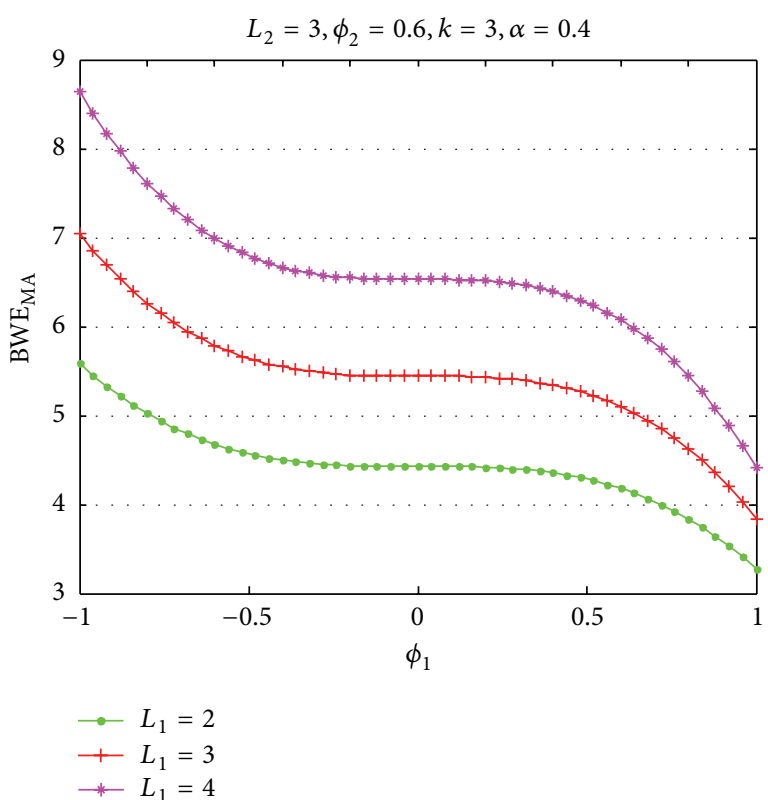

FIGURE 9: Impact of $\phi_{1}$ on bullwhip effect for different $L_{1}$ under the MA.

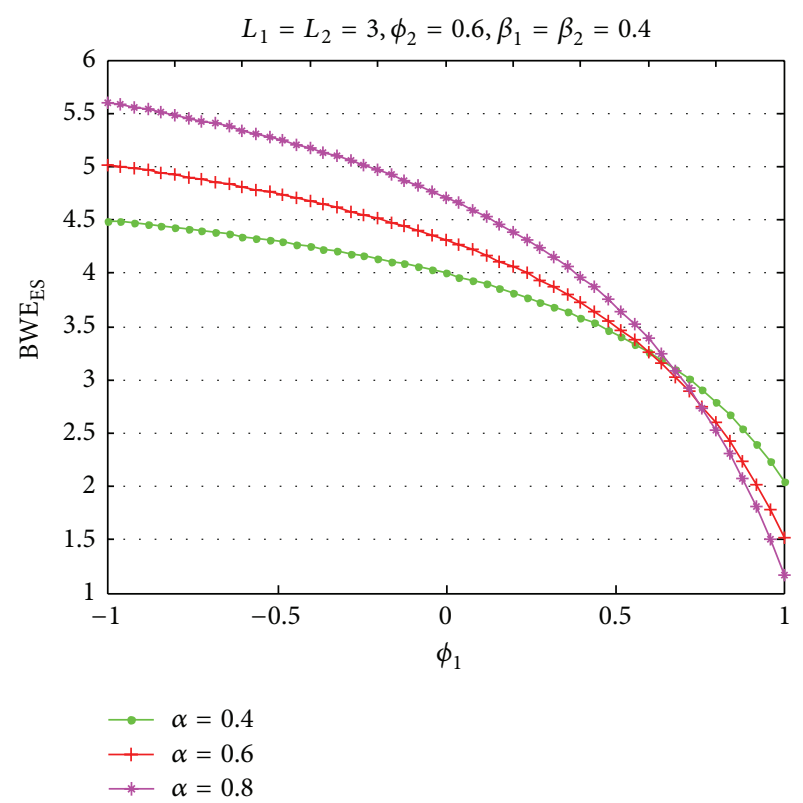

FIGURE 10: Impact of $\phi_{1}$ on bullwhip effect for different $\alpha$ under the ES.

4.3. The Analysis of Parameters under the ES Forecasting Method. Figures 10-14 simulate the expression of the bullwhip effect under the ES forecasting method to illustrate the impact of parameters on the bullwhip effect.

Figure 10 declares the impact of $\phi_{1}$ under various $\alpha$. The bullwhip effect decreases continuously with the increase of $\alpha$. When $\phi_{1}$ takes the value of 0.7 approximately, the bullwhip effect values of three different $\alpha$ are the same; when $\phi_{1}$ is less than 0.7 , the smaller the $\alpha$ is, the smaller the bullwhip effect value is; when $\phi_{1}$ is more than 0.7 , the result is opposite. 


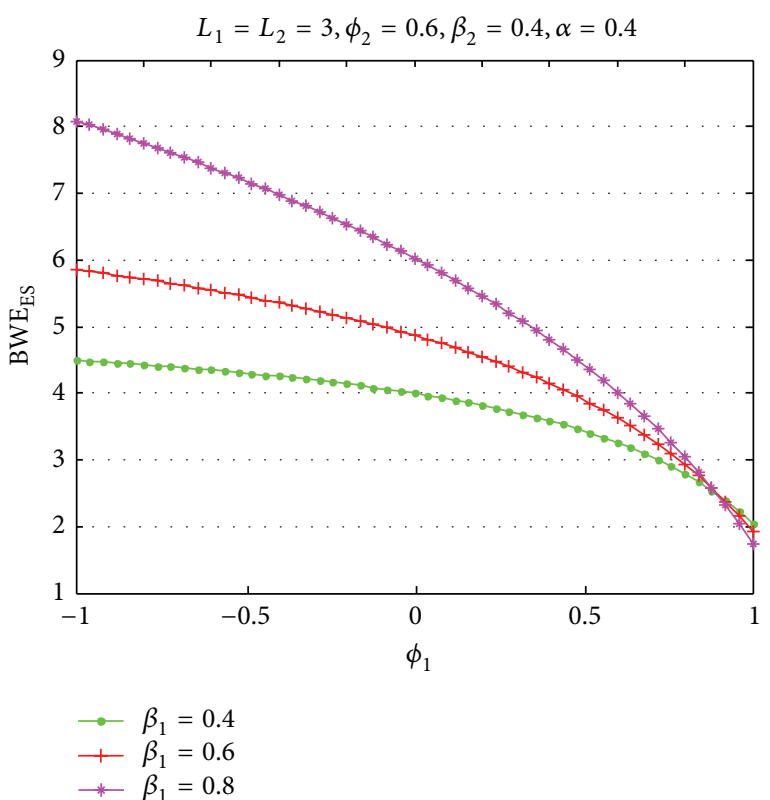

FIGURE 11: Impact of $\phi_{1}$ on bullwhip effect for different $\beta_{1}$ under the ES.

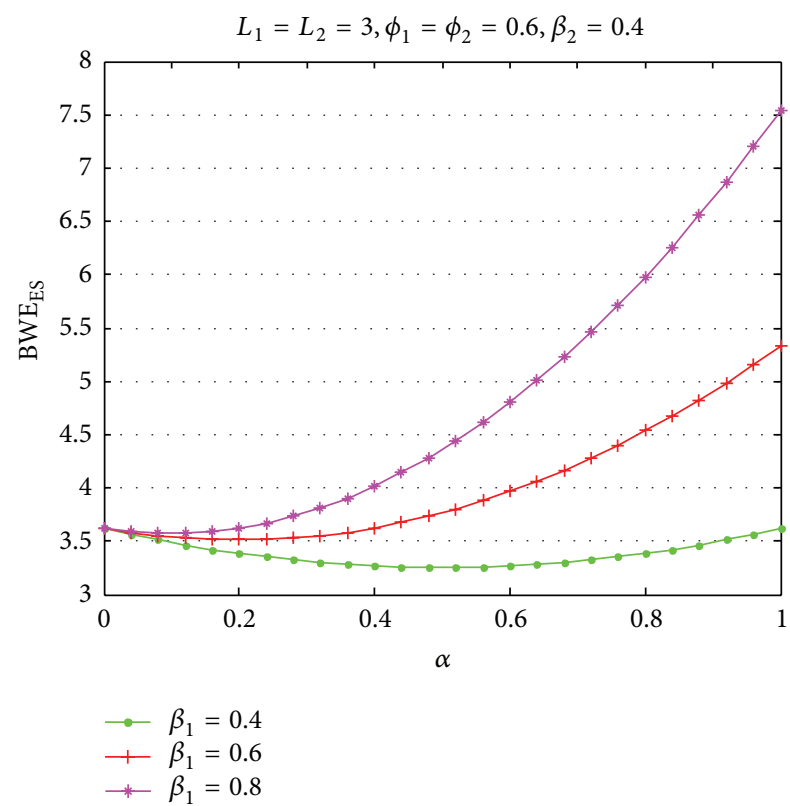

FIGURE 12: Impact of $\alpha$ on bullwhip effect for different $\beta_{1}$ under the ES.

As can be seen from Figure 11, the bullwhip effect decreases all the time in pace with the increase of $\phi_{1}$. And, in this situation, we can observe that the smaller the $\beta_{1}$ is, the smaller the bullwhip effect value is. This phenomenon shows that $\beta_{1}$ is an important factor to influence the bullwhip effect under the ES forecasting method.

Figure 12 indicates the impact of $\alpha$ on bullwhip effect for different $\beta_{1}$ under the ES. When $\beta_{1}$ takes the value of 0.4 , the bullwhip effect decreases slowly first, after that it increases

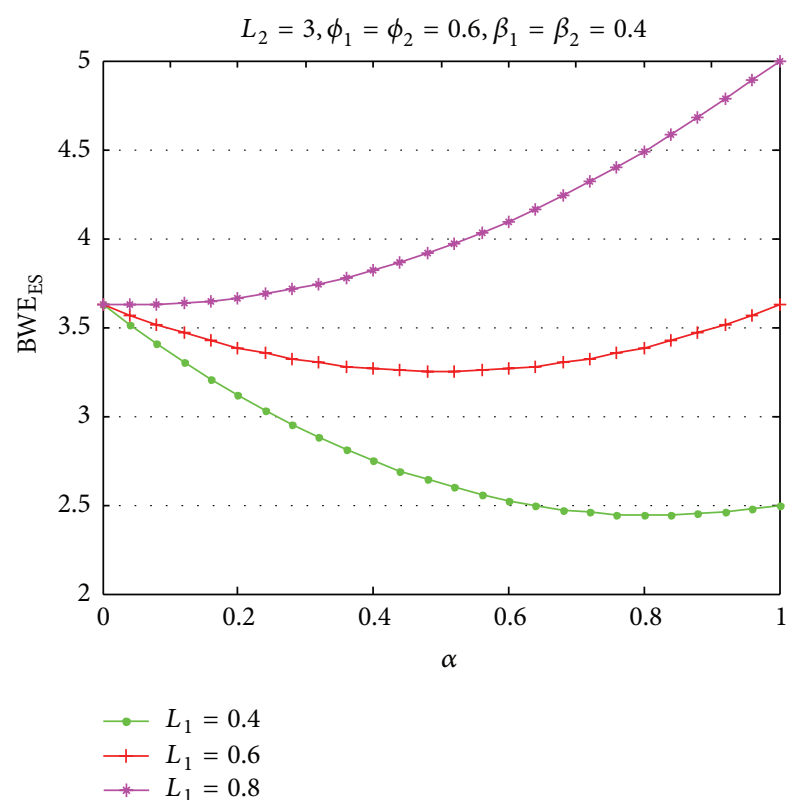

FIGURE 13: Impact of $\alpha$ on bullwhip effect for different $L_{1}$ under the ES.

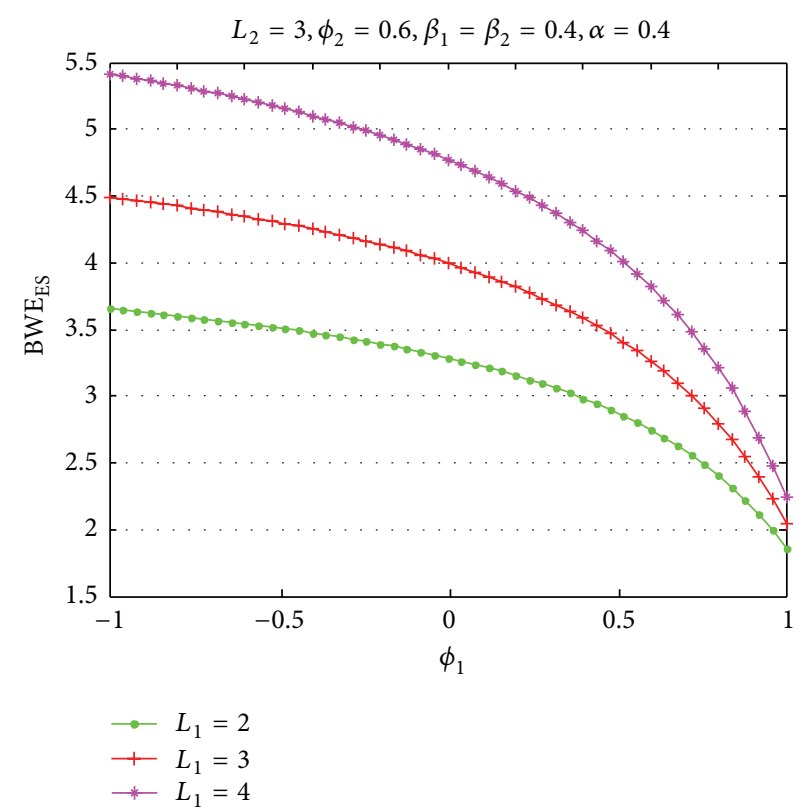

FIGURE 14: Impact of $\phi_{1}$ on bullwhip effect for different $L_{1}$ under the ES.

gradually. However, when the value of $\beta_{1}$ is 0.6 and 0.8 , the bullwhip effect keeps increasing rapidly.

Figure 13 reveals the impact of $\alpha$ on bullwhip effect for different $L_{1}$ under the ES. When $L_{1}$ takes the values of 0.4 and 0.6 , the bullwhip effect decreases slowly first, after that it increases gradually. And the minimum value of the bullwhip effect occurs as the value of $\alpha$ is 0.5 approximately. This phenomenon indicates that the intense competition between two retailers can increase the bullwhip effect. However, when the 


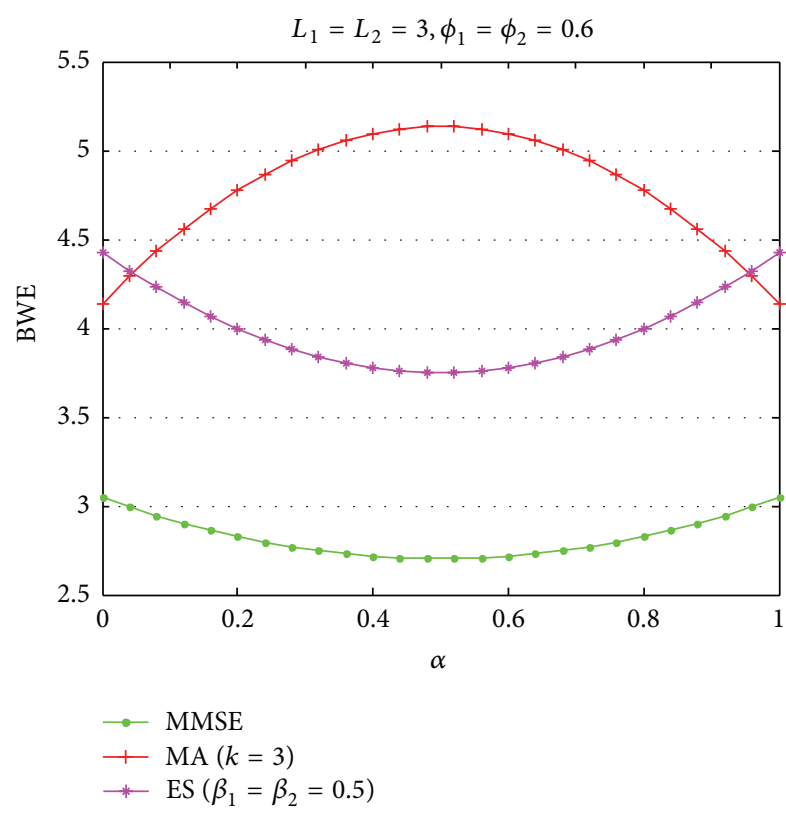

FIGURE 15: Comparison of three different forecasting methods by varying $\alpha(k=3)$.

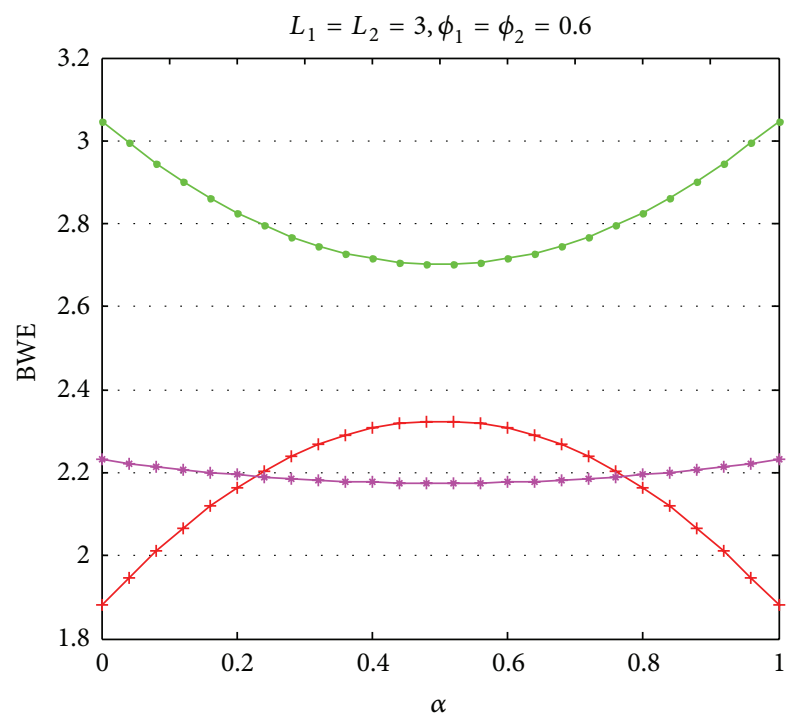

$\because \operatorname{MMSE}$
$\div \operatorname{MA}(k=9)$
$\because \operatorname{ES}\left(\beta_{1}=\beta_{2}=0.2\right)$

FIGURE 16: Comparison of three different forecasting methods by varying $\alpha(k=9)$.

value of $L_{1}$ is 0.8 , the bullwhip effect keeps increasing rapidly. This result is analogous with the situation in Figure 12.

Similar to Figure 11, Figure 14 shows the impact of $\phi_{1}$ on the bullwhip effect based on different $L_{1}$ under the ES. The bullwhip effect decreases all the time in pace with the increase of $\phi_{1}$. For different $L_{1}$, the smaller the $L_{1}$ is, the smaller the bullwhip effect value is. This situation indicates $L_{1}$ is also an

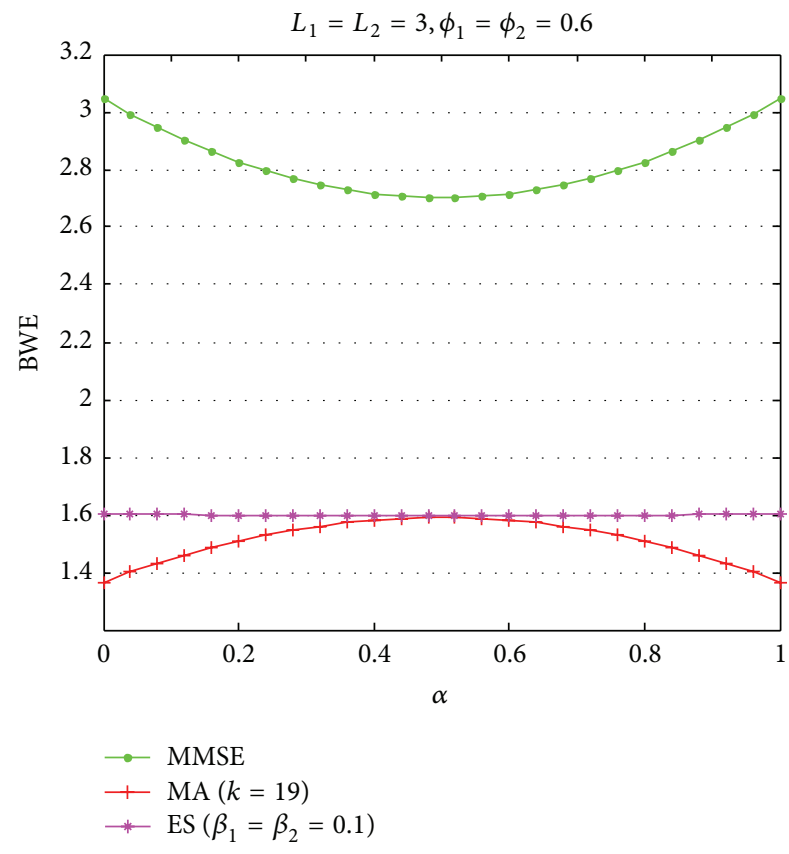

FIGURE 17: Comparison of three different forecasting methods by varying $\alpha(k=19)$.

important factor to influence the bullwhip effect under the ES forecasting method.

4.4. The Comparison of the Three Different Forecasting Methods. According to the analyses above, we select appropriate parameters to compare the bullwhip effect under three different forecasting methods. We set $L_{1}=L_{2}=3$ and $\phi_{1}=$ $\phi_{2}=0.6$. Then we choose appropriate $k, \beta_{1}$, and $\beta_{2}$. From Zhang [16], the MMSE method minimizes the variance of the forecasting error among all the linear forecasting methods. It obviously leads to the lowest average cost among the three forecasting approaches. If we impose the constraint of equal data age $(2 /(k+1))$ for the MA and ES forecasts by setting $\beta_{1}=\beta_{2}=2 /(k+1)$, we can also achieve that.

From Figures 15-17 the trends of the three bullwhip effects are the same. However the values of them change obviously.

According to Figure 15, we install $k=3$ and correspondingly $\beta_{1}=\beta_{2}=0.5$. We may find out that $\mathrm{BWE}_{\mathrm{MMSE}}$ is the lowest of all. $B W E_{\mathrm{MMSE}}$ and $\mathrm{BWE}_{\mathrm{ES}}$ decrease firstly to the minimum value and then increase with the increase of $\alpha$. However, $\mathrm{BWE}_{\mathrm{MA}}$ has opposite trend. When $\alpha$ is smaller than a certain value, $\mathrm{BWE} \mathrm{EA}_{\mathrm{MA}}$ is lower than $\mathrm{BWE}_{\mathrm{ES}}$; when $\alpha$ is larger than the certain value and smaller than another certain value, $\mathrm{BWE}_{\mathrm{MA}}$ is higher than $\mathrm{BWE}_{\mathrm{ES}}$; and when $\alpha$ is larger than another certain value, $\mathrm{BWE}_{\mathrm{MA}}$ is lower than $\mathrm{BWE}_{\mathrm{ES}}$ again. It means that the MMSE forecasting method is the best to forecast lead-time demand in this situation.

Figure 16 reveals that the bullwhip effects under three forecasting methods of $k=9$ and $\beta_{1}=\beta_{2}=0.2$ have the same trends with the circumstance of $k=3$ and $\beta_{1}=\beta_{2}=0.5$. But $\mathrm{BWE}_{\mathrm{MMSE}}$ is no longer the lowest of all, and it becomes the highest of the three oppositely. $\mathrm{BWE}_{\mathrm{MA}}$ and $\mathrm{BWE}_{\mathrm{ES}}$ are 
the same as Figure 15. It means that when $\alpha$ is larger than a certain value and smaller than another certain value, the ES forecasting method is the best. In the other situation, the MA is the most attractive one. We can come to the conclusion that we would better adopt ES forecasting method with the intense competition between two retailers.

In Figure 17, we set $k=19$ and $\beta_{1}=\beta_{2}=0.1$. In this circumstance, $\mathrm{BWE}_{\mathrm{MMSE}}$ is the highest all the time regardless different $\alpha$. BWE $\mathrm{ES}_{\mathrm{ES}}$ is a fixed value with the increase of $\alpha$. $\mathrm{BWE}_{\mathrm{MA}}$ is the lowest of all. This phenomenon reveals that the MA method is the best forecasting method whatever $\alpha$ is as long as $k=19$ or $k$ is larger.

\section{Conclusions}

This paper contrasts the bullwhip effect based on three different forecasting methods for a simple inventory system with an AR(1) demand. Previous research studied the bullwhip effect under different forecasting methods. However, the previous articles did not consider the impact of market share. This paper investigated the effect of the lead time, the autoregressive coefficient, and the market share on a bullwhip effect measure in a simple two-stage supply chain with two suppliers and two retailers, and the two retailers both employ the order-up-to inventory policy for replenishments.

We are surprised to find that the shorter the lead time is, the smaller the bullwhip effect is under three different forecasting methods. If the MMSE forecasting method is used, increasing autoregressive coefficient does not always reduce the bullwhip effect when the market share or lead time is varying. But increasing autoregressive coefficient can reduce the bullwhip effect effectively using the MA or ES forecasting method. Not only the autoregressive coefficient and lead time affect the bullwhip effect, but also market share and the average date age are two key factors to influence the bullwhip effect. Under MMSE and ES forecasting method the bullwhip effect can be reduced when the intense competition between the two retailers occurs. However, the bullwhip effect is proved to be maximum value when the intense competition between the two retailers occur using MA forecasting method. Average date age is proportional to the bullwhip effect when the MA method is used, and it is inversely proportional to the bullwhip effect when the ES method is used. And the bigger the average date age is, the smaller the bullwhip effect is.

The analyses above suggest that the bullwhip effect cannot be reduced by simply increasing the autoregressive coefficient. We must consider other parameters that affect the bullwhip effect as well. The MMSE forecasting method is likely to be the best method to qualify the bullwhip effect when the average date age is lower. But with the increase of the average date age the ES forecasting method seems better. And with the increase of the average date age, the bullwhip effect under the MA forecasting method turns into the lowest.

In the end, we must point out that quantifying the bullwhip effect and investigating its behavior are helpful for reducing the influence of the bullwhip effect in supply chains. However, firstly, controller may pay more attention to the inventory cost in practice. Hence, investigations of the impact of parameters for the inventory cost would be meaningful. Secondly, if we combine the control and bifurcation theory to study the bullwhip effect, we may produce better conclusions. There are also urgent needs for us to continue to study in this area. Only when we do more and more research, can we reduce the bullwhip effect effectively.

\section{Appendix}

(1) The Proof of (31) Is as Follows. After iteration computation for (2), we have

$$
\begin{aligned}
D_{1, t-1}= & \left(1+\phi_{1}+\cdots+\phi_{1}{ }^{k-1}\right) \alpha \delta_{1}+\phi_{1}{ }^{k} D_{1, t-k-1} \\
& +\alpha \phi_{1}{ }^{k-1} \varepsilon_{1, t-k}+\alpha \phi_{1}{ }^{k-2} \varepsilon_{1, t-k+1}+\cdots+\alpha \varepsilon_{1, t-1} \\
= & \frac{1-\phi_{1}{ }^{i+1}}{1-\phi_{1}} \alpha \delta_{1}+\phi_{1}{ }^{k} D_{1, t-k-1}+\sum_{j=0}^{k-1} \alpha \phi_{1}{ }^{k-1-j} \varepsilon_{1, t-k+j}
\end{aligned}
$$

So, we can get that

$$
\begin{aligned}
& \operatorname{Cov}\left(D_{1, t-1}, D_{1, t-k-1}\right) \\
& =\operatorname{Cov}\left(\frac{1-\phi_{1}{ }^{i+1}}{1-\phi_{1}} \alpha \delta_{1}+\phi_{1}{ }^{k} D_{1, t-k-1}\right. \\
& \left.\quad+\sum_{j=0}^{k-1} \alpha \phi_{1}{ }^{k-1-j} \varepsilon_{1, t-k+j}, D_{1, t-k-1}\right)=\phi_{1}{ }^{k} \operatorname{Var}\left(D_{1, t}\right), \\
& \operatorname{Cov}\left(D_{1, t-1}, D_{2, t-k-1}\right) \\
& =\operatorname{Cov}\left(\frac{1-\phi_{1}{ }^{i+1}}{1-\phi_{1}} \alpha \delta_{1}+\phi_{1}{ }^{k} D_{1, t-k-1}\right. \\
& \left.\quad+\sum_{j=0}^{k-1} \alpha \phi_{1}{ }^{k-1-j} \varepsilon_{1, t-k+j}, D_{2, t-k-1}\right) \\
& =\phi_{1}{ }^{k} \operatorname{Cov}\left(D_{1, t-k-1}, D_{2, t-k-1}\right)=\phi_{1}{ }^{k} \frac{\alpha}{1-\alpha} \operatorname{Var}\left(D_{2, t}\right) .
\end{aligned}
$$

Analogously, we may get the following:

$$
\begin{gathered}
\operatorname{Cov}\left(D_{1, t-k-1}, D_{2, t-1}\right)=\phi_{2}{ }^{k} \frac{\alpha}{1-\alpha} \operatorname{Var}\left(D_{2, t}\right), \\
\operatorname{Cov}\left(D_{2, t-1}, D_{2, t-k-1}\right)=\phi_{2}{ }^{k} \operatorname{Var}\left(D_{2, t}\right) .
\end{gathered}
$$


(2) The Proof of (39) Is as Follows. From (35),

$$
\begin{aligned}
\operatorname{Cov}\left(D_{1, t}, \widehat{D}_{1, t}\right) & =\operatorname{Cov}\left(D_{1, t}, \sum_{i=0}^{\infty} \beta_{1}\left(1-\beta_{1}\right)^{i} D_{1, t-i-1}\right) \\
& =\beta_{1} \sum_{i=0}^{\infty}\left(1-\beta_{1}\right)^{i} \operatorname{Cov}\left(D_{1, t}, D_{1, t-i-1}\right) \\
& =\beta_{1} \sum_{i=0}^{\infty}\left(1-\beta_{1}\right)^{i} \phi_{1}^{i+1} \operatorname{Var}\left(D_{1, t}\right) \\
& =\frac{\beta_{1} \phi_{1}}{1-\left(1-\beta_{1}\right) \phi_{1}} \operatorname{Var}\left(D_{1, t}\right), \\
\operatorname{Cov}\left(D_{1, t}, \widehat{D}_{2, t}\right) & =\operatorname{Cov}\left(D_{1, t}, \sum_{i=0}^{\infty} \beta_{2}\left(1-\beta_{2}\right)^{i} D_{2, t-i-1}\right) \\
& =\beta_{2} \sum_{i=0}^{\infty}\left(1-\beta_{2}\right)^{i} \operatorname{Cov}\left(D_{1, t}, D_{2, t-i-1}\right) \\
& =\beta_{2} \sum_{i=0}^{\infty}\left(1-\beta_{2}\right)^{i} \phi_{1}^{i+1} \frac{\alpha}{1+\alpha} \operatorname{Var}\left(D_{2, t}\right) \\
& =\frac{\beta_{2} \phi_{1}}{1-\left(1-\beta_{2}\right) \phi_{1}} \frac{\alpha}{1-\alpha} \operatorname{Var}\left(D_{2, t}\right) .
\end{aligned}
$$

The same,

$$
\begin{gathered}
\operatorname{Cov}\left(D_{2, t}, \widehat{D}_{2, t}\right)=\frac{\beta_{2} \phi_{2}}{1-\left(1-\beta_{2}\right) \phi_{2}} \operatorname{Var}\left(D_{2, t}\right), \\
\operatorname{Cov}\left(\widehat{D}_{1, t}, D_{2, t}\right)=\frac{\beta_{1} \phi_{2}}{1-\left(1-\beta_{1}\right) \phi_{2}} \frac{\alpha}{1-\alpha} \operatorname{Var}\left(D_{2, t}\right) .
\end{gathered}
$$

From (35), we can also get the following:

$$
\begin{aligned}
& \operatorname{Cov}\left(\widehat{D}_{1, t}, \widehat{D}_{2, t}\right) \\
& =\operatorname{Cov}\left(\sum_{i=0}^{\infty} \beta_{1}\left(1-\beta_{1}\right)^{i} D_{1, t-i-1}, \sum_{i=0}^{\infty} \beta_{2}\left(1-\beta_{2}\right)^{i} D_{2, t-i-1}\right) \\
& =\beta_{1} \beta_{2} \operatorname{Cov}\left(\sum_{i=0}^{\infty}\left(1-\beta_{1}\right)^{i} D_{1, t-i-1}, \sum_{i=0}^{\infty}\left(1-\beta_{2}\right)^{i} D_{2, t-i-1}\right) \\
& =\beta_{1} \beta_{2}\left(\sum_{i=0}^{\infty} \sum_{j=i+1}^{\infty}\left(1-\beta_{1}\right)^{i}\left(1-\beta_{2}\right)^{j} \phi_{1}^{j-i},\right. \\
& \left.\qquad \sum_{i=0}^{\infty} \sum_{j=0}^{i}\left(1-\beta_{1}\right)^{i}\left(1-\beta_{2}\right)^{j} \phi_{2}^{i-j}\right) \operatorname{Cov}\left(D_{1, t}, D_{2, t}\right)
\end{aligned}
$$

$$
\begin{aligned}
= & \beta_{1} \beta_{2}\left(\sum_{i=0}^{\infty}\left(1-\beta_{1}\right)^{i}\left(1-\beta_{2}\right)^{j} \frac{\phi_{1}\left(1-\beta_{2}\right)}{1-\left(1-\beta_{2}\right) \phi_{1}},\right. \\
& \left.\quad \sum_{i=0}^{\infty}\left(1-\beta_{1}\right)^{i}\left(1-\beta_{2}\right)^{i} \phi_{2}{ }^{i} \frac{1-\left(\left(1-\beta_{2}\right) / \phi_{2}\right)^{i+1}}{1-\left(\left(1-\beta_{2}\right) / \phi_{2}\right)}\right) \\
& \times \operatorname{Cov}\left(D_{1, t}, D_{2, t}\right) \\
= & \frac{\beta_{1} \beta_{2}\left(1-\phi_{1} \phi_{2}\left(1-\beta_{1}\right)\left(1-\beta_{2}\right)\right)}{\left(1-\left(1-\beta_{1}\right)\left(1-\beta_{2}\right)\right)\left(1-\left(1-\beta_{1}\right) \phi_{2}\right)\left(1-\left(1-\beta_{2}\right) \phi_{1}\right)} \\
& \times \frac{\alpha}{1-\alpha} \operatorname{Var}\left(D_{2, t}\right)
\end{aligned}
$$

\section{Conflict of Interests}

The authors declare that there is no conflict of interests regarding the publication of this paper.

\section{Acknowledgments}

The authors would like to thank the reviewers for their careful reading and for providing some pertinent suggestions. The research was supported by the National Natural Science Foundation of China (no. 61273231) and Doctoral Fund of Ministry of Education of China (Grant no. 20130032110073), and it was supported by Tianjin University Innovation Fund.

\section{References}

[1] J. W. Forrester, "Industrial dynamicsa major breakthrough for decision making," Harvard Business Review, vol. 36, no. 4, pp. 37-66, 1958.

[2] J. W. Forrester, Industrial Dynamics, MIT Press, Cambridge, Mass, USA, 1961.

[3] A. S. Blinder, "Inventories and sticky prices," American Economic Review, vol. 72, pp. 334-349, 1982.

[4] O. J. Blanchard, "The production and inventory behavior of American automobile industry," Journal of Political Economy, vol. 91, pp. 365-400, 1983.

[5] J. L. Burbidge, "Automated production control with a simulation capability," IFIP Working Paper WG 5(7), Copenhagen, Denmark, 1984.

[6] A. S. Blinder, "Can the production smoothing model of inventory behavior be safe?” Quarterly Journal of Economics, vol. 101, pp. 431-454, 1986.

[7] J. Kahn, "Inventories and the volatility of production," American Economics Review, vol. 77, pp. 667-679, 1987.

[8] J. Sterman, "Optimal policy for a multi-product, dynamic, nonstationary inventory problem," Management Science, vol. 12, pp. 206-222, 1989.

[9] H. L. Lee, V. Padmanabhan, and S. Whang, "Information distortion in a supply chain: the bullwhip effect," Management Science, vol. 43, no. 4, pp. 546-558, 1997.

[10] H. L. Lee, P. Padmanabhan, and S. Whang, "Bullwhip effect in a supply chain," Sloan Management Review, vol. 38, pp. 93-102, 1997. 
[11] R. Metters, "Quantifying the bullwhip effect in supply chains," Journal of Operations Management, vol. 15, no. 2, pp. 89-100, 1997.

[12] S. C. Graves, "A single-item inventory model for a nonstationary demand process," Manufacturing and Service Operations Management, vol. 1, pp. 50-61, 1999.

[13] F. Chen, Z. Drezner, J. K. Ryan, and D. Simchi-Levi, "Quantifying the bullwhip effect in a simple supply chain: the impact of forecasting, lead times, and information," Management Science, vol. 46, no. 3, pp. 436-443, 2000.

[14] F. Chen, J. K. Ryan, and D. Simchi-Levi, "The impact of exponential smoothing forecasts on the bullwhip effect," Naval Research Logistics, vol. 47, no. 4, pp. 269-286, 2000.

[15] K. Xu, Y. Dong, and P. T. Evers, “Towards better coordination of the supply chain," Transportation Research E: Logistics and Transportation Review, vol. 37, no. 1, pp. 35-54, 2000.

[16] X. Zhang, "The impact of forecasting methods on the bullwhip effect," International Journal of Production Economics, vol. 88, no. 1, pp. 15-27, 2004.

[17] H. T. Luong, "Measure of bullwhip effect in supply chains with autoregressive demand process," European Journal of Operational Research, vol. 180, no. 3, pp. 1086-1097, 2007.

[18] T. T. H. Duc, H. T. Luong, and Y. D. Kim, "Effect of the thirdparty warehouse on bullwhip effect and inventory cost in supply chains," International Journal of Production Economics, vol. 124, no. 2, pp. 395-407, 2010.

[19] H. R. Karimi, N. A. Duffie, and S. Dashkovskiy, "Local capacity $H_{\infty}$ control for production networks of autonomous work systems with time-varying delays," IEEE Transactions on Automation Science and Engineering, vol. 7, no. 4, pp. 849-857, 2010.

[20] B. Nepal, A. Murat, and R. Babu Chinnam, "The bullwhip effect in capacitated supply chains with consideration for product lifecycle aspects," International Journal of Production Economics, vol. 136, no. 2, pp. 318-331, 2012.

[21] S. Dashkovskiy, H. R. Karimi, and M. Kosmykov, "A LyapunovRazumikhin approach for stability analysis of logistics networks with time-delays," International Journal of Systems Science, vol. 43, no. 5, pp. 845-853, 2012.

[22] S. Dashkovskiy, H. R. Karimi, and M. Kosmykov, "Stability analysis of logistics networks with time-delays," Production Planning and Control, vol. 24, no. 7, pp. 567-574, 2013.

[23] A. Mehrsai, H. Karimi, K. Thoben, and B. Scholz-Reiter, "Application of learning pallets for real-time scheduling by the use of radial basis function network," Neurocomputing, vol. 101, pp. 82-93, 2013.

[24] A. Mehrsai, H. Karimi, and B. Scholz-Reiter, "Toward learning autonomous pallets by using fuzzy rules, applied in a Conwip system," International Journal of Advanced Manufacturing Technology, vol. 64, no. 5-8, pp. 1131-1150, 2013.

[25] J. H. Ma and X. G. Ma, "A comparison of bullwhip effect under various forecasting techniques in supply chains with two retailers," Abstract and Applied Analysis, vol. 2013, Article ID 796384, 14 pages, 2013.

[26] W. Shen and J. H. Jiang, "Parameter matching analysis of hydraulic hybrid excavators based on dynamic programming algorithm ", Journal of Applied Mathematics, vol. 2013, Article ID 615608, 10 pages, 2013.

[27] W. Shen, J. Jianga, X. Sub, and H. R. Karimic, "Control strategy analysis of the hydraulic hybrid excavator," Journal of the Franklin Institute, 2014.
[28] T. T. H. Duc, H. T. Luong, and Y. Kim, "A measure of bullwhip effect in supply chains with a mixed autoregressive-moving average demand process," The European Journal of Operational Research, vol. 187, no. 1, pp. 243-256, 2008. 


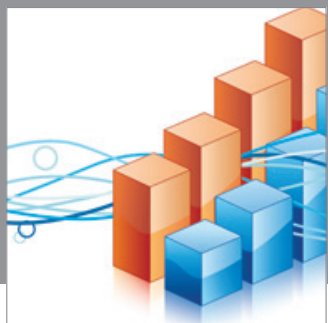

Advances in

Operations Research

mansans

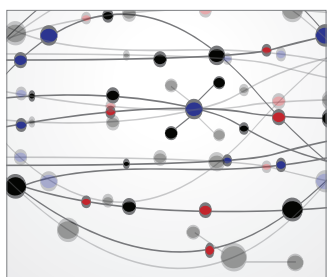

The Scientific World Journal
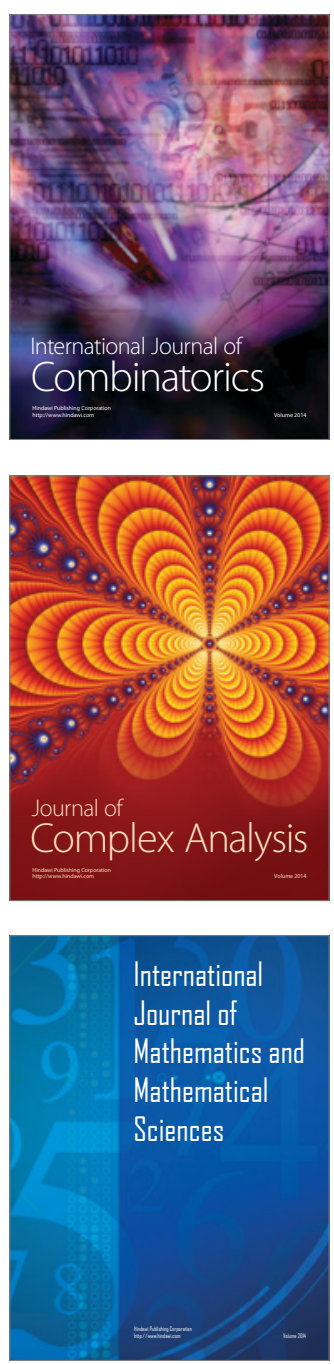
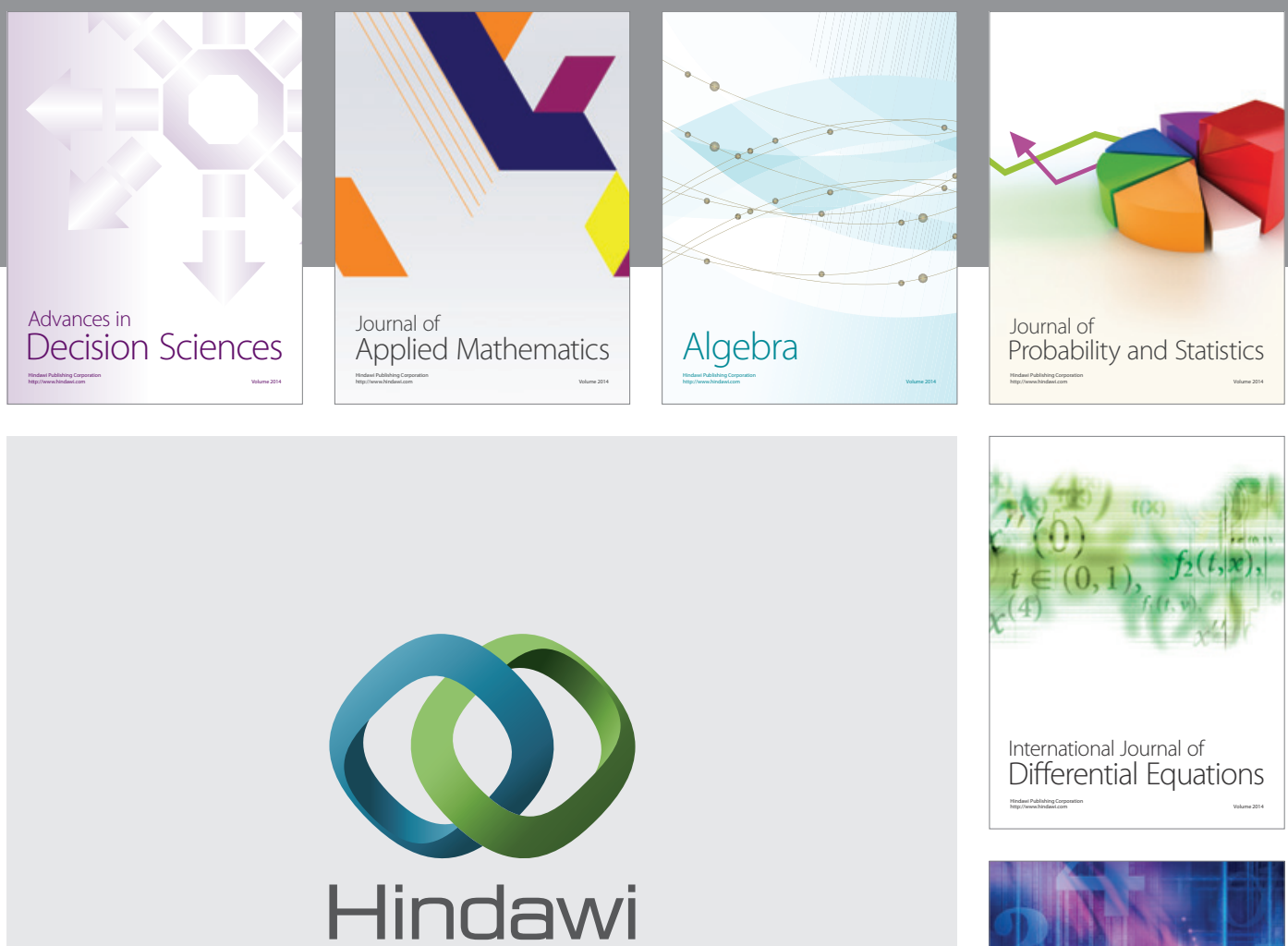

Submit your manuscripts at http://www.hindawi.com
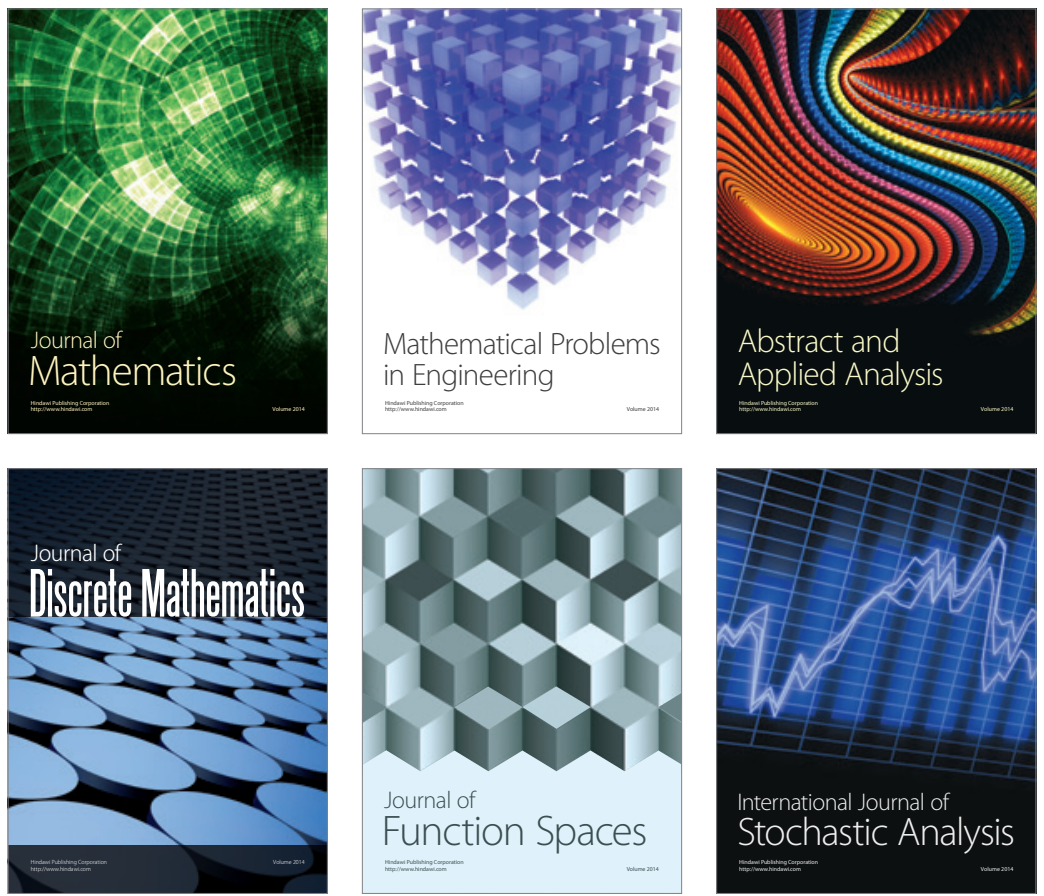

Journal of

Function Spaces

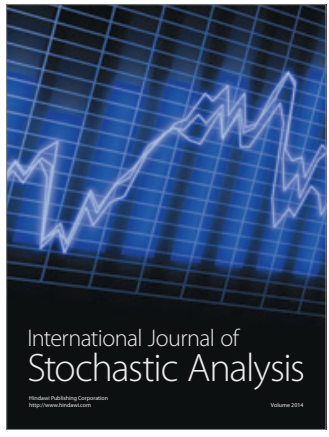

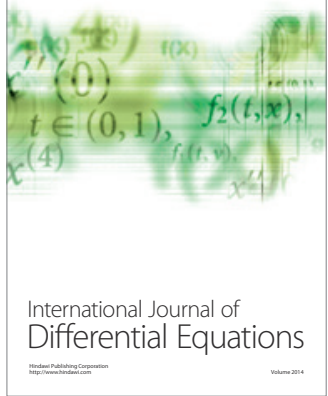
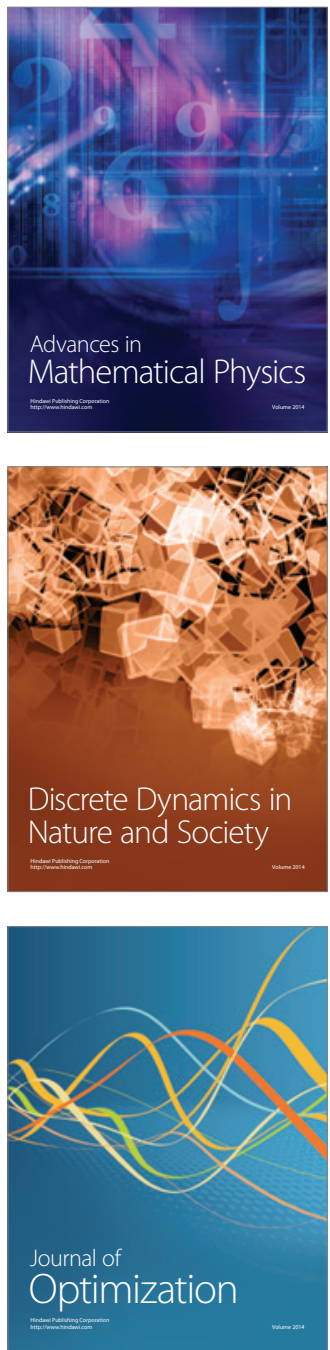